\title{
Purinoreceptors and ectonucleotidases control ATP-induced calcium waveforms and calcium-dependent responses in microglia
}

\author{
Byeong Jae Chun ${ }^{1} \quad$ Surya Aryal ${ }^{2} \quad$ Bin Sun $^{1}$ \\ Josh Bruno $^{1} \quad$ Chris Richards ${ }^{2} \quad$ Adam D. Bachstetter ${ }^{3}$ \\ Peter M. Kekenes-Huskey ${ }^{1}$
}

June 22, 2021

${ }^{1}$ Department of Cell and Molecular Physiology, Loyola University Chicago

${ }^{2}$ Department of Chemistry, University of Kentucky

${ }^{3}$ College of Medicine, University of Kentucky 


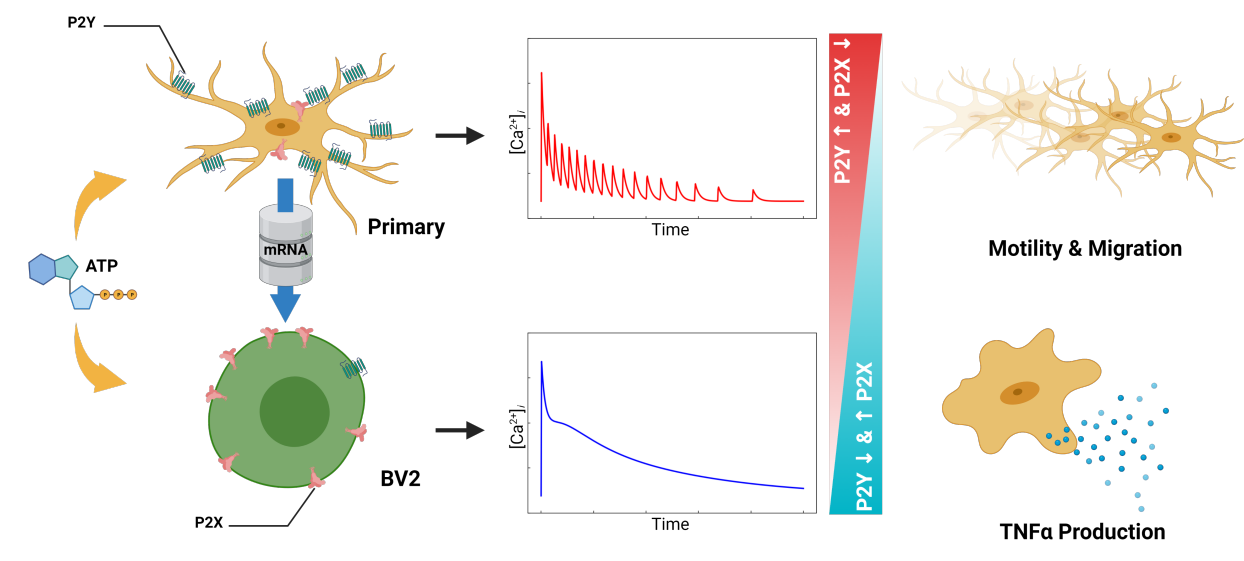

Figure 1: $\quad$ Table of Contents Graphic. Schematic of the computational study. ATP triggers the activation of $\mathrm{P} 2 \mathrm{Y}$ and $\mathrm{P} 2 \mathrm{X}$ receptors expressed in microglia (left column). The activated receptors generate intracellular $\mathrm{Ca}^{2+}$ signals (middle column) that contribute to microglial migration and cytokine production (right column). .

\section{Abstract}

Adenosine triphosphate (ATP) drives microglia motility and cytokine production by activating P2X- and P2Y- class purinergic receptors with extracellular ATP and its metabolites. Purinergic receptor activation gives rise to diverse intracellular $\mathrm{Ca}^{2+}$ signals, or waveforms, that differ in amplitude, duration, and frequency. Whether and how these diverse waveforms influence microglia function is not well established. We developed a computational model trained with published primary murine microglia studies. We simulate how purinoreceptors influence $\mathrm{Ca}^{2+}$ signaling and migration and how purinoreceptor expression modifies these processes. Our simulation confirmed that P2 receptors encode the amplitude and duration of the ATP-induced calcium waveforms. Our simulations also implicate CD39, an ectonucleotidase that rapidly degrades ATP, as a regulator of purinergic receptor-induced $\mathrm{Ca}^{2+}$ responses. We, therefore, next evaluated how purinoreceptors and ectonucleotidase work in tandem. Our modeling results indicate that small transients are sufficient to promote motility, while large and sustained transients are needed for cytokine responses. Lastly, we predict how these phenotypical responses vary in a BV2 microglia cell line using published P2 receptor mRNA data to illustrate how our computer model can be extrapolated to diverse microglia subtypes. These findings provide important insights into how differences in purinergic receptor expression influence the microglia's responses to ATP. 


\section{Introduction}

Microglia are the central nervous system (CNS) macrophages. They contribute homeostatic and innate immune responses when subject to a spectrum of molecular stimuli, including those associated with infection and cellular damage. Microglia respond to these stimuli by migrating, undergoing changes in gene programming, secreting cytokines and chemokines to engage the adaptive immune response, and phagocytosing foreign bodies. Many details of these complex signaling pathways controlling microglial responses to such cues are beginning to emerge, including those mediated by adenosine triphosphate (ATP) and its nucleotide derivatives (45).

Extracellular ATP invokes $\mathrm{Ca}^{2+}$ waveforms in microglia that trigger or influence cytokine and motility responses $(59 ; 35 ; 33)$, as well as a broad set of microglial signaling pathways $(42 ; 56)$. In other cell types, the waveform of an induced $\mathrm{Ca}^{2+}$ signal, that is, its duration, amplitude and frequency, has been shown to selectively control intracellular processes including phosphorylation, gene transcription and mechanical responses (11). Despite these observations, it has yet to be determined if the properties of $\mathrm{Ca}^{2+}$ waveforms in microglia exhibit similar selective control of their physiological functions.

ATP-dependent responses in microglia are mediated by purinergic (P2) receptors. P2 receptors are broadly categorized into two classes: ionotropic $(\mathrm{P} 2 \mathrm{X})$ and metabotropic $(\mathrm{P} 2 \mathrm{Y})$ receptors. Ionotropic $\mathrm{P} 2 \mathrm{X}$ receptor $(P 2 X)$ receptors are non-selective cation channels widely expressed in cells throughout the CNS including microglia. Of these, $P 2 X 7$ and $P 2 X 4$ tend to be the most highly expressed $P 2 X$-class receptors in microglia $(42 ; 2)$. In our previous work $(9)$, we developed a computational model demonstrating that $P 2 X$ activation promotes the production of a pro-inflammatory cytokine, tumor necrosis factor alpha $(\mathrm{TNF} \alpha)$. However, microglia also express P2Y receptor $(P 2 Y)$ receptors that comprise $\mathrm{G}$ protein coupled receptors (GPCR), which mediate pathways including endoplasmic reticulum (ER) $\mathrm{Ca}^{2+}$ release $(42 ; 56)$. There are several prominent $P 2 Y$ receptors present in microglia such as P2Y2, P2Y6, P2Y12, and P2Y13 (32). In principle, both classes of P2 receptors contribute to ATPmediated responses in microglia, but their cocurrent contributions have yet to be determined in quantitative detail.

Microglia exhibit changes in motility, e.g. the extension and retraction of plasma membrane, in response to ATP and can migrate toward sources of ATP. $\mathrm{Ca}^{2+}$ transients that coincide with directed motility and migration have been observed in microglia $(58 ; 59 ; 35 ; 24)$. Given the diverse $\mathrm{Ca}^{2+}$ waveforms induced by $\mathrm{P} 2$ activation, there is an intriguing possibility that microglia adopt unique cell responses to different waveforms that could select for migration versus inflammatory behaviors. However, it remains to be determined if variable $\mathrm{Ca}^{2+}$ waveforms are just a consequence of ATP stimulation or if they selectively influence cell funcions.

$\mathrm{Ca}^{2+}$ waveforms and the capacity for cell migration in response to ATP are dependent on P2 expression and activity. P2 subtype expression can vary considerably among microglial subpopulations and activation states $(30 ; 15$; 5). As an example, resting, in vivo microglia are characterized by having high P2Y12 receptor ( $P 2 Y 12)$ expression and comparatively low expression of $P 2 X 4$ and $P 2 X 7(27 ; 14 ; 42)$, whereas classically activated microglia upregulate $P 2 X 4$ and downregulate P2Y12 (27). This motivated our hypothesis that P2X and $\mathrm{P} 2 \mathrm{Y}$ co-expression in microglia subpopulations enable the cells to encode unique $\mathrm{Ca}^{2+}$ waveforms that prime migration versus inflammatory responses (Fig. 1). 
To investigate this hypothesis, we extended our model of $P 2 X 4 / P 2 X 7$ activation in microglia (9) to include contributions from $P 2 Y$-class receptors. The extended model includes G-protein mediated $\mathrm{Ca}^{2+}$ signaling and the activation of pathways implicated in microglia migration. This approach complements prior computational studies of $\mathrm{Ca}^{2+}$ responses induced by $P 2 X$ receptors $(43 ; 9)$ and metabotropic receptors that promote intracellular $\mathrm{Ca}^{2+}$ release $(16 ; 68 ; 67)$. With this contribution, we specifically examined how $P 2 X$ - and $P 2 Y$-class purinoreceptors encode ATP-triggered $\mathrm{Ca}^{2+}$ waveforms in microglia, how these waveforms are modulated by enzymes like ectonucleotidases, and how these waveforms control migration and cytokine responses.

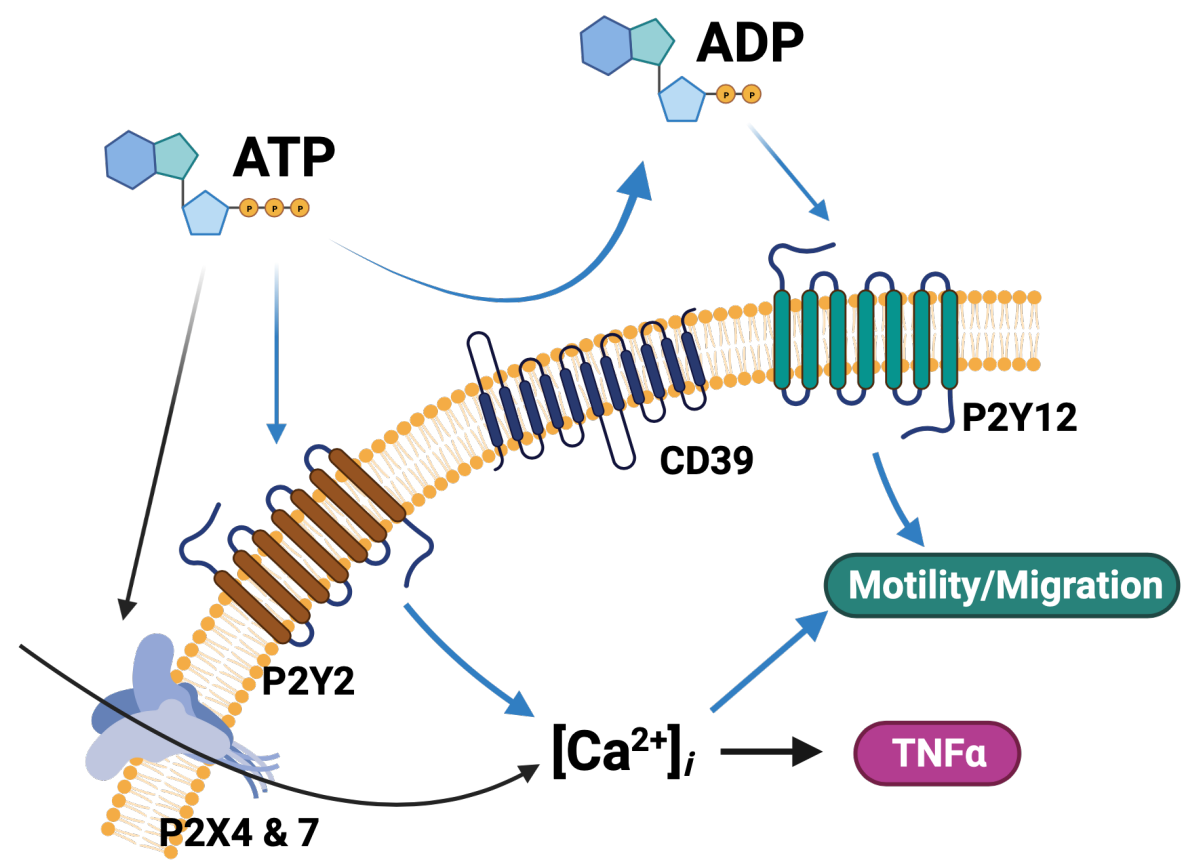

\section{Cytoplasm}

Figure 2: $\quad$ Schematic of the computational microglia model, which simulates the ATP-dependent activation of P2X- and P2Y-class receptors. The simulations also account for increases in intracellular $\mathrm{Ca}^{2+}$, cell migration, and $\mathrm{TNF} \alpha$ cytokine production following $\mathrm{P} 2$ receptor activation. 


\section{Materials and methods}

\subsection{The computational model}

We extended the computational model of $P 2 X 4$ and $P 2 X 7$-mediated $\mathrm{Ca}^{2+}$ signals and TNF $\alpha$ production described in Chun et al(9) to include $P 2 Y$-dependent contributions to migration and cytokine responses (see Fig. 2). The original model consisted of differential-equation based descriptions of $P 2 X 4$ and $P 2 X 7$ gating (9) $\mathrm{Ca}^{2+}$ influx via $P 2 X$ channels with the production of $\mathrm{TNF} \alpha$. The aforementioned model has been extended with the addition of pathways such as phosphoinositide 3-kinase (PI3K) activation and phosphorylation of Akt to provide a quantitative measure of microglial migration with respect to ATP (see Fig. 2) (59).

P2X4 and P2X7 models used in this study (see Fig. 9A) were implemented as described in Chun et al(9), which were originally derived from published models $(85 ; 78 ; 43)$. Currents were related to intracellular $\mathrm{Ca}^{2+}$ by converting the inward current into the $\mathrm{Ca}^{2+}$ influx as described in our previous work (9).

For the metabotropic receptor contributions, we assumed that P2Y2 and P2Y6 activation promotes the disassembly of their $G_{\alpha q}$ subunit, wherafter PLC is activated to promote the generation of Inositol trisphosphate $\left(\mathrm{IP}_{3}\right)$ and Diacylglycerol (DAG) from PIP2 $(42 ; 16)$ (see Fig. 9B). We described this process using a mathematical model introduced by Cutherbertson et al (16) for $I P_{3^{-}}$ mediated $\mathrm{Ca}^{2+}$ oscillations in oocytes. The model includes an agonist receptor for $G_{\alpha q}$ protein activation, $G_{\alpha q}$-dependent Phospholipase C (PLC) activation, PLC-dependent $I_{3}$ synthesis, and we also assume $P 2 Y$ is activated by ATP, though it is likely that the activation occurs through the ADP product of ectonucleotidases (detailed in Sect. S.5.) DAG in turn indirectly inhibits G-protein dependent PLC activation by catalyzing PKC activity. The major challenge associated with validating contributions of specific $P 2 Y$ receptors to experimentally measured $\mathrm{Ca}^{2+}$ transients is isolating the contribution of the specific receptor from other $P 2 Y$ receptor contributions. We lump oscillatory transients into G-protein dynamics, PLC activity, and $I P_{3}$-mediated $\mathrm{Ca}^{2+}$ release from the ER. Although a number of scientific communications have discussed the correlation between P2Y12/13 receptor activation and intracellular $\mathrm{Ca}^{2+}$ fluctuations via indirect pathways $(40 ; 42)$, for model simplicity, we created a lumped $P 2 Y$ model. $I P_{3}$ molecules trigger the activation of $I P_{3}$ receptors that induce $\mathrm{ERCa}^{2+}$ release. Concurrently, as the cytosolic $\mathrm{Ca}^{2+}$ rises following $I P_{3}$ receptor opening, DAG and $\mathrm{Ca}^{2+}$ promote protein kinase $\mathrm{C}(\mathrm{PKC})$-based inhibition of $G_{\alpha q}$ and the P2Y receptors.

Ectonucleoside triphosphate diphosphohydrolase-1, also known as CD39, is expressed in the surface of microglial plasma-membrane and play an important role in microglial migration by balancing ATP and adenosine molecules (25). We used the model of ATP decomposition into ADP and AMP by CD39 introduced in the (47) (see Fig. 9C). We assume the agonist for P2X and P2Y-class that mediates $\mathrm{Ca}^{2+}$ fluctuations is ATP whereas P2Y12 is specifically stimulated by ADP.

Many models for cell migration have been reported in the literature. These includes models for actin polymerization $(52 ; 64)$, multi-cellular migration (17), and tissue-level simulations of tumor growth (83). In microglia, migration is associated with pathways triggered by P2Y12 activation (see Fig. 9D). A G $\mathrm{G}_{a-}$ containing GPCR, P2Y12, ultimately promotes PI3K activation in response to ADP. Within the process of activating PI3K, the active form of PLC dephos- 
phorylates PIP3, the product of which mediates the PI3K/Akt pathway (46). According to a series of work done by Ohsawa et al $(58 ; 59)$, it is clear that the presence $\mathrm{Ca}^{2+}$ rise in inducing the chemotaxis of microglia is reflected as a sensitivity of PI3K activation to the intracellular $\mathrm{Ca}^{2+}$ concentration. In Ohsawa's work(58), the inhibition of PI3K substantially reduces the phosphorylation of Akt, which not only results in the suppression of membrane ruffling and migration. In addition, we also introduce the involvement of calmodulin (CaM) that is an indirect component of chemotaxis process mediated via MLCK pathway, according to Yao et al(86).

For describing the dynamics of cytosolic $\mathrm{Ca}^{2+}$, we implemented and validated $\mathrm{Ca}^{2+}$ uptake and release from the ER by SERCA and $I P_{3} R$, respectively. Basal $\mathrm{Ca}^{2+}$ levels are restored by the Sarcoplasmic/endoplasmic reticulum calcium ATPase (SERCA) pump and the sodium/calcium exchanger (NCX) as described in (9).

With respect to the ER $\mathrm{Ca}^{2+}$ load, we utilized ratiometric data from ATPtreated microglial cells presented by Ikeda et al (35) to estimate ER $\mathrm{Ca}^{2+}$ release via $I P_{3} R$ receptor $\left(I P_{3} R\right)$. The authors obtained a series of $\mathrm{Ca}^{2+}$ transients to infer the distinct contributions made by ionotropic and metabotropic receptors. The authors utilized two ATP concentrations $(100 \mu \mathrm{M}$ and $1 \mathrm{mM})$ to selectively activate a target receptor(s) $(P 2 X 4$ vs. $P 2 X 7)$. In another experimental setup, $P 2 X 7 \mathrm{R}$ RNA $i$ to silence $P 2 X 7$ receptor that was used to isolate $P 2 X 7$ contributions to the overall $\mathrm{Ca}^{2+}$ transients under constant ATP stimulation. For model validation, we converted the ratiometric data to concentration data by normalizing the cytosolic fluorescent intensity of resting microglia to $100 \mathrm{nM}$.

We neglect store operated calcium entry $(S O C E)$ given that this mechanism of $\mathrm{Ca}^{2+}$ entry occurs well after $\mathrm{Ca}^{2+}$ currents mediated directly by $5-10$ minutes after ATP stimulation $(40 ; 35 ; 1 ; 5)$. Limitations of this simplification are discussed in Limitations (Sect. 6).

TNF $\alpha$ production via NFAT (see Fig. 9E) was implemented as described in Chun et al (9). Particular process we included in this work is that $\mathrm{Ca}^{2+}$ mediated CaM/calcineurin activation promotes the translocation of NFAT into nucleus (13), which mediates the transcription of TNF $\alpha$ mRNA (33).

\subsubsection{Numerical solution of the computational model}

The resulting system of differential equations were numerically solved and optimized via Python (ver. 3.6) and Gotran (ver. 2020.2.0.), see (9) for details. As previously described $(74 ; 9)$, the Generalized ordinary differential equations (ODE) (ordinary differential equation) Translator was utilized to implement the microglial model. The Gotran Python module was utilized to make use of our previously written Python-based routines for simulation and analysis. The SciPy function, ODEINT, that employs the LSODA algorithm for stiff ODEs (60) was used in the numerical integration of the microglia model. A time-step for the 10-min numerical integration was of $0.1 \mathrm{~ms}$. These computations generate as output the time-dependent values of model 'states', such as intracellular $\mathrm{Ca}^{2+}$ or the open gates of the $P 2 X$ channels. Model fitting was further tuned and refined by a genetic algorithm (reviewed in (71)) that iteratively improved assigned parameters, such as the rate of $\mathrm{Ca}^{2+}$ leak and $P 2 X 4 / P 2 X 7$ conductance. Parameters for the model components are summarized in Sect. S.1. Based on these sets of parameters, our key model outputs were $\mathrm{Ca}^{2+}$ transients with respect to ATP exposure duration and concentration, 
as well subsequent changes in other states including PI3K and Akt for which experimental reference data were available. Experimentally-measured outputs, such as $\mathrm{Ca}^{2+}$ transient decay time and amplitude, were used to optimize the model parameters by minimizing the error between model predicted outputs and experiment.

All code written and simulation input files in support of this publication are publicly available at https://github.com/bending456/2021p2xp2y. Generated data are available upon request.

\subsection{Experimental details}

\subsubsection{Microglia Culture and imaging}

For live cell calcium imaging, 96 well plates were used for BV2 cell culture. Cells were plated in a density of 5000 per wells 2 days prior to imaging. In the day of calcium imaging, the cells were incubated at $37^{\circ} \mathrm{C}$ with $5 \% \mathrm{CO}_{2}$ with $1 \mu \mathrm{g} / \mathrm{mL}$ Fluo-4 AM (Thermo Fischer Scientific) in Leibovitz's L-15 medium for 45 minutes. Excess Fluo-4 AM was washed by Leibovitz's L-15 Medium and again incubated in Leibovitz's L-15 Medium for 30 minutes. A custombuilt, wide-field, epifluorescence microscope having a 10X objective with 488 $\mathrm{nm}$ laser was used for taking time lapse images. 20-minute time lapse movies were taken for different concentrations of ATP (ThermoFischer Scientific) with first 10 minute without adding ATP and rest after adding ATP.

For data in Fig. 7, $\mathrm{Ca}^{2+}$ measurements were taken every 0.5 mins throughout the experimental window. For each ATP dose, approximately 48 cells were selected to calculate the $\mathrm{Ca}^{2+}$ transients (as indicated by pixel intensity). For each cell, the ATP-induced $\mathrm{Ca}^{2+}$ transient was normalized with respect to the control stage, namely, the average pixel intensity of the control stage was subtracted from the pixel trace of the whole time course.

Detection of ATP-induced Ca transients The recorded images via the aforementioned calcium imaging protocol were processed via custom python routines. The TIF file from experiment is processed as a $3 \mathrm{D}$ matrix with a specific shape defined by (T,M,N) where $T$ denotes the time-index, $M \times N$ is the image dimensionality (in the unit of pixels). The pixel intensity (gray-scale) was stored in 16-bit color depth. As the first step, the cell detection protocol identifies cells from the image and provides its quantity. Specifically, the intensity at each pixel of the image was summed up along the time-index to get a total image with shape $(M \times N)$. The total image was then subject to a log transformation and normalization. The histogram of pixel intensities of the normalized image was plotted to help identify a custom thresholding value. Parameters used for acquisition of these signals are embedded in the source code provided with this project. After determining the thresholding value, the normalized total image was converted into a binary image with intensities greater than the thresholding value identified as cell bodies with the rest as background. The detected cells in the binary image satisfying the aforementioned condition were recognized and labeled. Using this information, the original TIF gray-scale image was utilized to record the change in the pixel intensity at each cell location, the average trace of which later represented the ATP-mediated $\mathrm{Ca}^{2+}$ transient of each cell.

We subsequently analyzed the $\mathrm{Ca}^{2+}$ transients before and after addition of different concentrations of ATP by taking time lapse images using widefield excitation. To normalize the data, we first calculated the average $\mathrm{Ca}^{2+}$ signal or fluorescent intensity in the control phase, the first 10 minutes without ATP. We 
then identified $\mathrm{Ca}^{2+}$ transients by dividing the entire time trace by the average fluorescent intensity. This was used to identify changes in the fluorescence signal.

Detection of BV2 motility Using the bright-field data collected for ATP treated BV2 cells, we selected cells that exhibited displacements within the first 20 frames directly after ATP treatment, which corresponds to 600 seconds in total. To measure displacements, we manually selected reference points within a given BV2 cell process at the initial time point and its approximate position at the final (10th) frame, from which a vector was defined. The resolution of the brightfield data was approximately $1.6 \mu \mathrm{m} /$ pixel, therefore the length in pixels of the displacement vector was converted into micrometers.

\section{Results}

\section{1 $\mathrm{Ca}^{2+}$ waveform jointly is shaped by $\mathrm{P} 2$ receptors and ectonucleotidases}

We developed a computer model of metabotropic (P2Y-class) and ionotropic (P2X-class) purinergic receptors to simulate $\mathrm{Ca}^{2+}$ signaling in microglia (Fig. 2). These $\mathrm{Ca}^{2+}$ signals are induced by extracellular ATP and its metabolites binding to P2 receptors $(42 ; 56)$. We therefore expanded a published model of $\mathrm{P} 2 \mathrm{X}$ receptor activation (9) to include $P 2 Y$ in order to investigate how both purinoreceptor classes influence intracellular $\mathrm{Ca}^{2+}$ transients. We first implemented and validated a model for G-protein mediated $I P_{3}$ generation and $I P_{3}$ receptor-mediated $\mathrm{ER} \mathrm{Ca}^{2+}$ release contributed by Cuthbertson et al (16) that we adapted to reflect P2Y-mediated $\mathrm{Ca}^{2+}$ waveforms (see Fig. 3). We then validated predicted $\mathrm{Ca}^{2+}$ waveforms generated by both P2X- and P2Y-class receptors against data collected in primary microglia by Ikeda et al(35). 

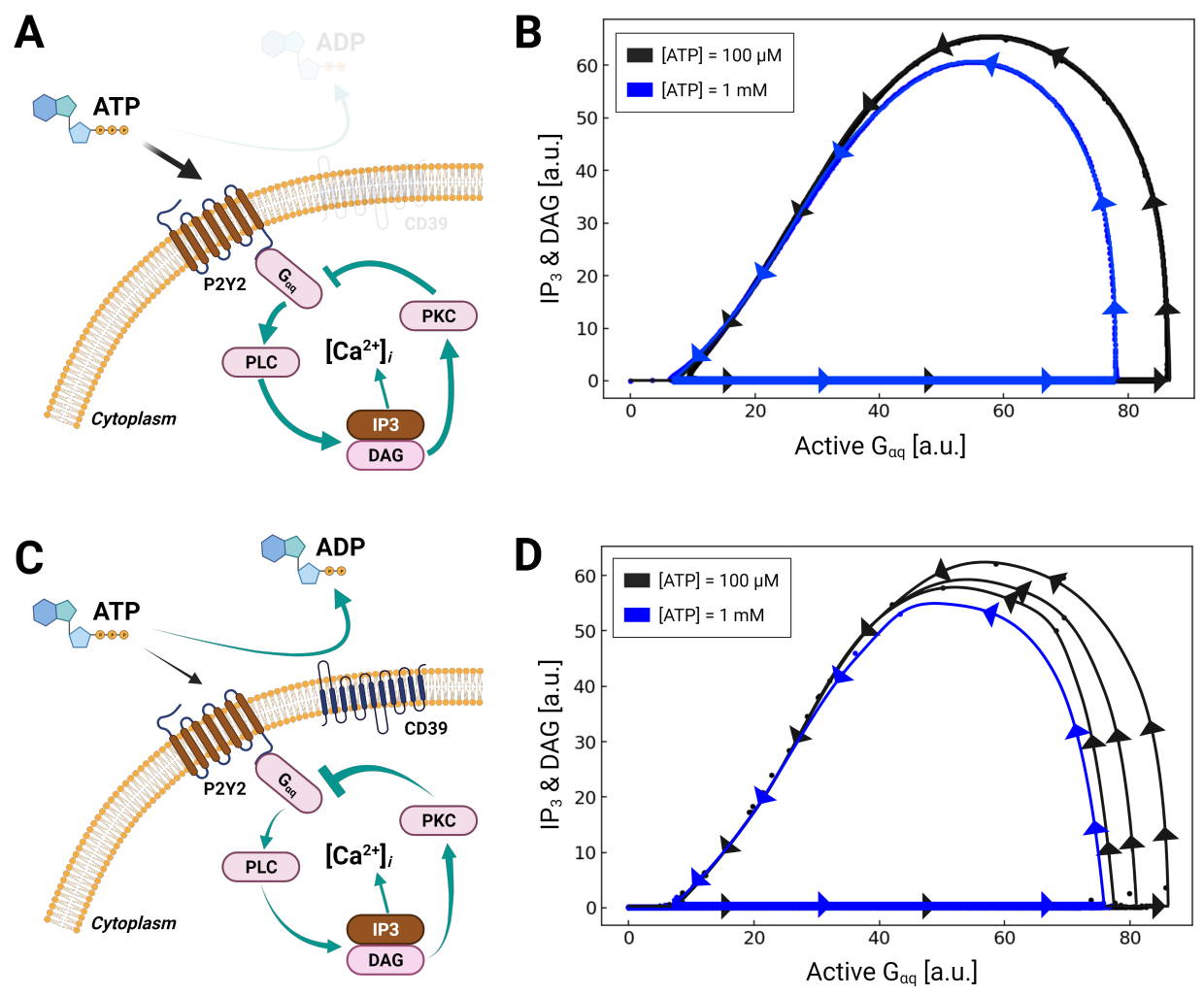

Figure 3: A) Schematic of P2Y2-dependent activation of $I P_{3}$ production via $G_{\alpha q}$. B) Predictions of oscillatory $I P_{3}$ and DAG production as a function of activated $G_{\alpha q}$ in response to $100 \mu \mathrm{M}$ (black) and $1 \mathrm{mM}$ (blue) ATP. C) and D) are equivalent to $\mathrm{A}$ and $\mathrm{B}$, except that the simulation includes the hydrolysis of ATP by the ectonucleotidase CD39. . 


\subsection{1 $G_{\alpha q}$ signaling via $P 2 Y$}

$P 2 Y$-driven $I P_{3}$ signaling begins with the activation of $G_{\alpha q}$-protein, which stimulates Phospholipase $\mathrm{C}$ (PLC) to produce Inositol trisphosphate $\left(I P_{3}\right)$ and Diacylglycerol (DAG) from $P I P_{2}$ (Fig. $3 \mathrm{~A}$ ). This is followed by ER $\mathrm{Ca}^{2+}$ release via $I P_{3}$-stimulated $I P_{3} R$ s. Negative-feedback arises in this system as DAG produced by PLC activates Protein kinase C (PKC), which inhibits $G_{\alpha q}$. In Fig. 3B we demonstrate that the activation of $P 2 Y$ by ATP and subsequently $G_{\alpha q}$ results in periodic fluctuations in DAG and $I P_{3}$ concentrations. This is evident as stationary cycles in Fig. $4 \mathrm{~A}$, where increases in active $G_{\alpha q}$ were accompanied by increases in $I P_{3}$ and DAG; these increases continued until active $G_{\alpha q}$ was nearly saturated at 80 [a.u], whereafter $I P_{3}$ and DAG rapidly decayed to zero as active $G_{\alpha q}$ was depleted. Larger oscillations in $G_{\alpha q}$ activation and $I P_{3}$ production were evident with $1 \mathrm{mM}$ ATP relative to $1 \mathrm{\mu M}$.

Stable $I P_{3}$ oscillations are reported in many cells types and are a prototypical example of negative-feedback circuits $(82 ; 41)$. Interestingly, microglia exhibit both oscillatory and aperiodic $\mathrm{Ca}^{2+}$ transients, which suggests that the underlying $I P_{3}$ synthesis is not exclusively periodic. Oscillations in feedback biochemical circuits are determined by the kinetics of the underlying enzymes, therefore non-oscillatory $I P_{3}$ signals are theoretically possible and would manifest as single-peak $\mathrm{Ca}^{2+}$ 'waveforms' (35). We demonstrate in Fig. S3) how variations in the parameters underlying P2Y-frequency dependent $G_{\alpha q}$ activation can yield stable oscillations versus aperiodic behavior. Namely, by reducing the input parameter $k g_{p 2 y}$ that controls the rate of $G_{\alpha q}$ activation, the system reverts to nonoscillatory behavior. Similar effects can be shown by varying other parameters describing the $G_{\alpha q}$ negative-feedback circuit, which suggests that the activity of proteins comprising the $G_{\alpha q} / I P_{3}$ signaling pathway determine whether $I P_{3}$ and thereby $\mathrm{Ca}^{2+}$ are oscillatory versus non-oscillatory.

$I P_{3}$ invokes intracellular $\mathrm{Ca}^{2+}$ release from the endoplasmic reticulum via $I P_{3}$ receptors. We therefore fit the model's predicted $I P_{3}$-induced $\mathrm{Ca}^{2+}$ transients to reproduce experimental data collected by Ikeda et al (35). Namely, we fit the initial peak amplitude $\left(\left[\mathrm{Ca}^{2+}\right]_{i}=180 \mathrm{nM}\right)$ to match the Ikeda et al data in MG5 microglial cells treated with $1 \mathrm{mM}$ ATP (35), for which P2X7 was knocked-out to isolate $\mathrm{P} 2 \mathrm{Y}$ contributions. We reflected this condition in our overall $\mathrm{Ca}^{2+}$ signaling model by disabling the $P 2 X$-mediated currents. In Fig. 4b, we compare our predictions of $I P_{3}$-mediated $\mathrm{Ca}^{2+}$ release following a 10-minute $1 \mathrm{mM}$ ATP treatment (blue) relative to the experimentally-measured transients from Ikeda et al(dashed black). After this initial peak, our model predicts an oscillatory $\mathrm{Ca}^{2+}$ waveform that is complemented by decreases in ER $\mathrm{Ca}^{2+}$ owing to $I P_{3}$ receptor activation (Fig. S2). While the predicted $\mathrm{Ca}^{2+}$ waveform resembles the oscillations observed by Ikeda et al, the waveform did not exhibit decay with time, in contrast with experiment. 
A

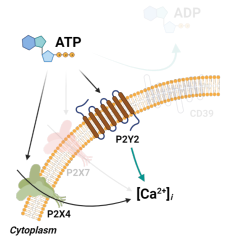

\section{C}

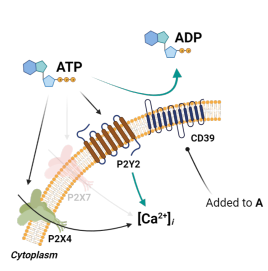

$\mathbf{E}$

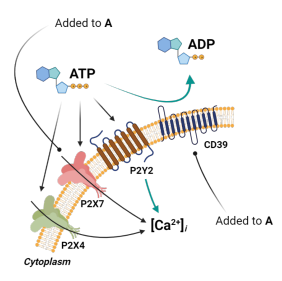

B

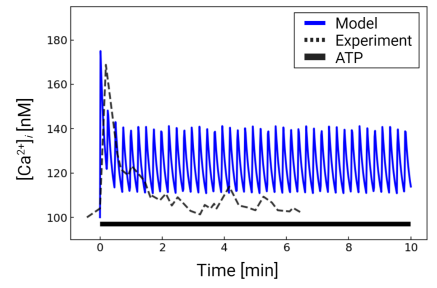

D

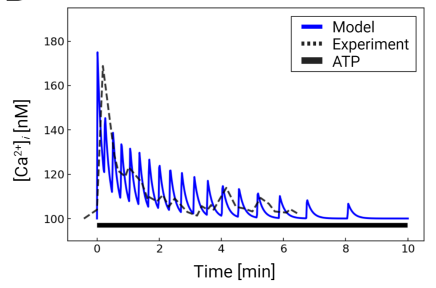

$\mathbf{F}$

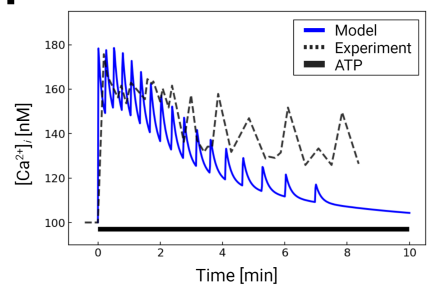

Figure 4: $\quad$ A) Schematic for $\mathrm{Ca}^{2+}$ waveforms generated by P2X4 and P2Y2 in response to $1 \mathrm{mM}$ ATP for 5 minutes. P2X7 contributions were blocked in this simulation (P2X7 KO). Schematic C) is analogous to A), but includes CD39 nucleotidase degradation of ATP (P2X7 KO). E) Schematic for $\mathrm{Ca}^{2+}$ waveforms generated in a control system comprising P2X4, P2X7 and P2Y2 and includes CD39 nucleotidase activity (WT). B, D, and F) Comparison of predicted (blue) and experimentally-measured (35) (dashed) $\mathrm{Ca}^{2+}$ transients, corresponding to the schematic A, C, and E, respectively. Results excluding CD39 are shown in Fig. S6 . 
While a variety of mechanisms could be attributed to this discrepancy, such as the desensitization of $P 2 Y$ receptors to ATP (38), we speculated that the availability of ATP for triggering $P 2 Y$ was the prominent source of error. Normally, extracellular ATP is rapidly degraded into adenosine diphosphate (ADP) and adenosine monophosphate (AMP) by ectonucleotidases (47). In microglia, NTPDase1 (CD39) is the primary ectonucleotidase isoform responsible for ATP degradation (25). To represent this contribution, we implemented a mathematical model from (47) to simulate ectonucleotidase-catalyzed hydrolysis of ATP into ADP and AMP. Our implementation is validated against experimental data in Fig. S4, for which nucleotide concentrations were measured in COS-7 cells over a one-hour time interval (47). Importantly, these data demonstrate that the ATP pool was depleted within minutes; this depletion was accompanied by a transient ADP pool that was maximal at $\mathrm{t}=4 \mathrm{~min}$ and subsequently decayed to zero. After including ectonucleotidase contributions in our microglia model, the predicted cytosolic $\mathrm{Ca}^{2+}$ transients decayed in a manner consisted with experiment (Fig. 4B) without additional fitting. Interestingly, we found that the frequency of predicted oscillations decreased with time, which we attributed to the dose-dependent decrease in $G_{\alpha q}$ activated by the P2Y receptors (Fig. S3). Hence, our simulations provide strong evidence that ectonucleotidases, and specifically CD39, play a prominent role in shaping the $\mathrm{Ca}^{2+}$ waveform by controlling the nucleotide pool available to purinoreceptors.

After validating our model of P2Y-induced $\mathrm{Ca}^{2+}$ dynamics, we restored $\mathrm{P} 2 \mathrm{X}$ receptor contributions and compared model predictions against analogous experiments in Fig. 4. We again simulated the system subjected to $1 \mathrm{mM}$ ATP for ten minutes with and without ectonucleotidase activity (shown in Fig. 4 and Fig. S6). In contrast to the $P 2 X 7$ knock-out data, we observed a modestly higher peak $\mathrm{Ca}^{2+}$ transient amplitude that was followed by a prolonged plateau as would be expected from $P 2 X 7$ currents (20). Predicted $\mathrm{Ca}^{2+}$ oscillations decayed toward resting $\mathrm{Ca}^{2+}$ levels after approximately ten minutes, albeit at a faster rate than observed experimentally. We report similar findings upon $100 \mathrm{uM}$ ATP treatment in Fig. S5, which favored $P 2 X 4$ activation. Altogether, our data suggest that a diverse ensemble of $\mathrm{Ca}^{2+}$ waveforms are invoked by controlling P2 receptor activation and nucleotide availability.

\subsection{P2 mediated $\mathrm{Ca}^{2+}$ waveforms contribute to migration}

We next examined how $P 2 Y$ activation and $P 2 Y$-mediated $\mathrm{Ca}^{2+}$ waveforms control cell migration and motility (see Fig. 5). P2Y 12 activation is essential for chemotactic migration and rapid motility responses in ATP-stimulated microglia $(58 ; 59 ; 36 ; 42)$. P2Y 12 receptors primarily activate the G-protein, $\mathrm{G}_{a i}$, and thereby promote Akt phosphorylation via PI3K, which in turn activates mechanisms underlying cell migration in microglia (59). 
A

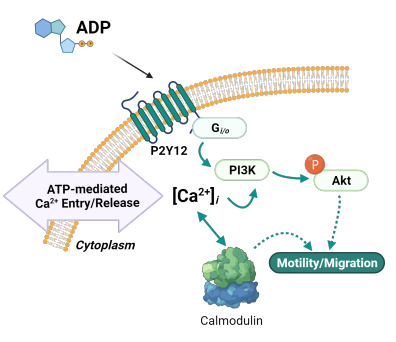

C

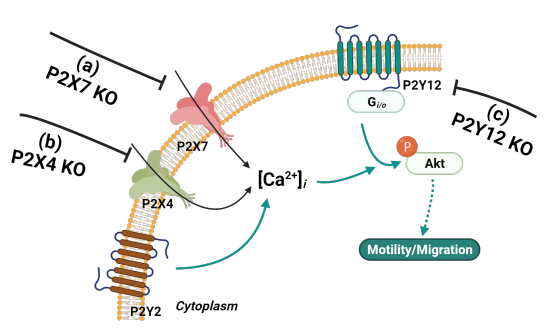

B

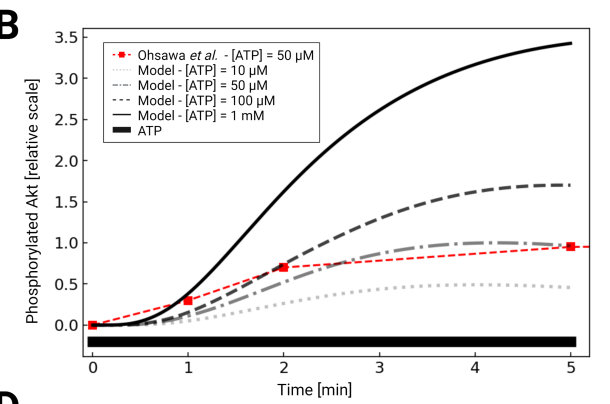

D

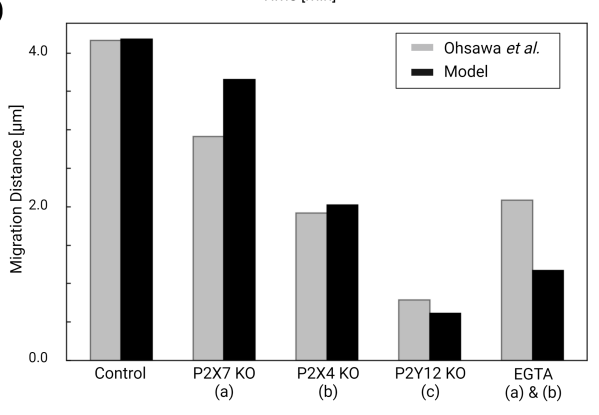

Figure 5: $\quad$ A) Schematic of Akt phosphorylation via P2Y12- and P2Ymediated $\mathrm{Ca}^{2+}$ signaling pathways in response to ATP. B) Predicted $p$ Akt expression as a function of time in response to $50 \mathrm{uM}$ to $1 \mathrm{mM}$ ATP applied for 5 minutes. Experimental data for $50 \mathrm{uM}$ ATP from Ohsawa et al are presented in red. C) Schematic of P2Y12- and Ca-mediated migration in response to ATP, assuming control, P2X7 knockout (KO) (a), P2X4 KO (b) and P2Y12 KO (c) conditions. D) Predicted migration distances (black) versus experimental measurements by Ohsawa et al under control and a-c conditions. . 
We first fitted our $p$ Akt responses under $50 \mu \mathrm{M}$ ATP treatment to reproduce trends observed by Ohsawa et al. For this process, we utilized the timedependent phosphorylation of Akt following the activation of PI3K and the data with various $\mathrm{P} 2 \mathrm{KO}$ conditions to tune the sensitivity of $\mathrm{PI} 3 \mathrm{~K} / p \mathrm{Akt}$ pathways to the intercellular $\mathrm{Ca}^{2+}$ fluctuations. The resulting fit is shown in Fig. 5A, which indicates maximal $p$ Akt levels were obtained at about 4 minutes and were in close agreement with experiment. P2Y12 activation peaked at this time given that its primary agonist, ADP, is maximal at 4 minutes due to ectonucleotidase activity (see Fig. S4). We show that Akt phosphorylation increased with increasing ATP concentration, as $100 \mu \mathrm{M}$ and $1 \mathrm{mM}$ ATP treatments resulted in 50 and $300 \%$ increases in pAkt relative to the $50 \mu \mathrm{M}$ treatment.

Curiously, this process has been shown to depend on extracellular $\mathrm{Ca}^{2+}$, as inhibition of $P 2 X$ receptors (PPADS and TNP-ATP for $P 2 X 7$ and $P 2 X 4$, respectively) and chelation of extracellular $\mathrm{Ca}^{2+}$ by EGTA all diminish both $p$ Akt levels and migration $(58 ; 59 ; 36)$. We therefore augmented our computational model to include $\mathrm{Ca}^{2+}$-dependent $\mathrm{PI} 3 \mathrm{~K} / p \mathrm{Akt}$ activation, as a step toward investigating the extents to which purinoreceptor-encoded $\mathrm{Ca}^{2+}$ waveforms influence migration (18). To determine the $\mathrm{Ca}^{2+}$ dependence of PI3K activation, we referred to data from Ohsawa et al (58) that reported Akt phosphorylation following $P 2 Y 12, P 2 X 7$ or $P 2 X 4$ knockout in neonatal Wistar rat microglia. Under $P 2 Y 12$ knock-out, they observed a $90 \%$ reduction in $p$ Akt upon treatment of $50 \mu \mathrm{M}$ ATP for 5 mins relative to WT. We attributed the remaining $10 \%$ of the $p$ Akt phosphorylation to $\mathrm{Ca}^{2+}$ influx from the $\mathrm{P} 2 \mathrm{X}$ receptors. This was motivated by our observations that 1) P2X4 in particular generated prominent $\mathrm{Ca}^{2+}$ transients with micromolar ATP treatments (59) and 2) that EGTA treatment nullified $P 2 X$-mediated $\mathrm{Ca}^{2+}$ transients and significantly reduces PI3K activation (59). Indeed, we predict in Fig. S8C that EGTA treatment reduced $p$ Akt by $75 \%$, which implicated extracellular $\mathrm{Ca}^{2+}$ as a significant contribution to microglia migration.

We next examined the effects of $P 2 X 4$ and $P 2 X 7$ inhibition on PI3K activation, and subsequently, $p \mathrm{Akt}$, as both conduct extracellular $\mathrm{Ca}^{2+}$. Without additional refitting our model predicted $15 \%$ and $40 \%$ reductions in $p$ Akt levels solely from $P 2 X 4$ and $P 2 X 7$ inhibition, respectively, in close agreement with Ohsawa (see Fig. 5B), These significant reductions upon nullifying $P 2 X$ contributions therefore implicate ionotropic receptors in phosphorylating Akt. We additionally verified that $P 2 Y 12$ knock-out all but eliminates Akt phosphorylation. Lastly, we predict that blunted ectonucleotidase hydrolase function enhances $p$ Akt phosphorylation, which suggests that prolonged $\mathrm{Ca}^{2+}$ waveforms further promote Akt activation (58) (shown in Fig. S8B).

\subsubsection{Microglial migration}

P2Y12, PI3K, Akt and extracellular $\mathrm{Ca}^{2+}$ are necessary for migration $(58 ; 59)$. This is in part supported by data from Ohsawa et al demonstrating microglia with inhibited PI3K exhibit in negligible migration when treated with ATP (58). We therefore assumed microglia migration rates were proportional to $p$ Akt levels in accordance with data from Ohsawa (58). Those data suggested that ATP-treated microglia migrate distances of approximately 48 micron following one hour of $50 \mathrm{\mu M}$ treatment. We interpolated these data to a distance $4 \mathrm{\mu m}$ following five minutes of stimulation. The $p$ Akt-dependent migration rate was then fit to yield the this short migration distance following integration of the $p$ Akt levels over five minutes. We tested our fitted model by reporting 
migration distances upon inhibition of $P 2 X 4, P 2 X 7$, and $P 2 Y 12$ (see Fig. 5C). Without additional fitting, our simulated data nearly reproduced the $75 \%$ reduction in migration following $P 2 Y 12$ knock-out that was reported by Ohsawa et al. Intermediate reductions in migration distances following $P 2 X 7$ and $P 2 X 4$ knockout were also comparable to data from Ohsawa et al (Fig. 5D). We further demonstrate that reducing ectonucleotidase activity enhanced migration, as was already observed for our predicted $p$ Akt levels and $\mathrm{Ca}^{2+}$ waveform durations (shown in Fig. S9). Importantly, these simulated data confirm that $P 2 Y 12 \mathrm{KO}$ dramatically reduced, but did not entirely eliminate migration; together with the reductions in migration following $P 2 X$ knock-outs, these data implicate the significant role of extracellular $\mathrm{Ca}^{2+}$ in mediating migration.

\section{3 $\mathrm{Ca}^{2+}$ waveforms and their impact on migration versus cytokine responses}

Our data thus far indicate that microglia have robust $\mathrm{Ca}^{2+}$ responses to $\mathrm{P} 2$ receptor activation that promote migration. We previously showed in (9) that cytokine synthesis and release in microglia was driven by intracellular $\mathrm{Ca}^{2+}$ signaling. This raised the question as to how ATP-induced $\mathrm{Ca}^{2+}$ waveforms determined migration versus inflammatory cytokine responses in microglia. To answer this question, we predicted migration distances as a function of $\mathrm{Ca}^{2+}$ waveform amplitude and oscillation frequency when subject to $200 \mathrm{uM}$ ATP for 5 minutes in Fig. 6. The amplitudes and frequencies were controlled by modulating the $I P_{3}$ pathway parameter $k g_{p 2 y}$. As a measure of cytokine responses, we report predicted TNF $\alpha$ released levels, using our validated model from (9). For reference, the dashed box indicates baseline migration and $\mathrm{TNF} \alpha$ responses for the model when subject to $200 \mu \mathrm{M}$ ATP. Per (33) et al, secreted TNF $\alpha$ was undetectable under $1 \mathrm{hr}$ and reached a maximum concentration (425 pg/10 6 cells) for $3 \mathrm{mM}$ ATP after 6 hours. Our model predictions indicate that both migration and TNF $\alpha$ mRNA levels increase with increasing $\mathrm{Ca}^{2+}$ waveform frequency and amplitude (Fig. 6). Although TNF $\alpha$ responses were predicted to increase at a greater rate than migration for increasing $\mathrm{Ca}^{2+}$ waveform frequency and amplitude, we anticipate produced $\mathrm{TNF} \alpha$ would nonetheless be undetectable at 5 minutes. This is based on observations by Hide et al that minimal TNF $\alpha$ (10 pg/10 cells) was measured at $1 \mathrm{hr}$, even with ATP treatments exceeding $1 \mathrm{mM}(3 \mathrm{mM})$. Importantly, our model demonstrates that 1) both migration and TNF $\alpha$ production were positively correlated with the frequency and amplitude of the $\mathrm{Ca}^{2+}$ waveform and 2) migration was induced insignificant TNF $\alpha$ responses when the $\mathrm{Ca}^{2+}$ waveforms were of short duration, low amplitude and low frequency. 

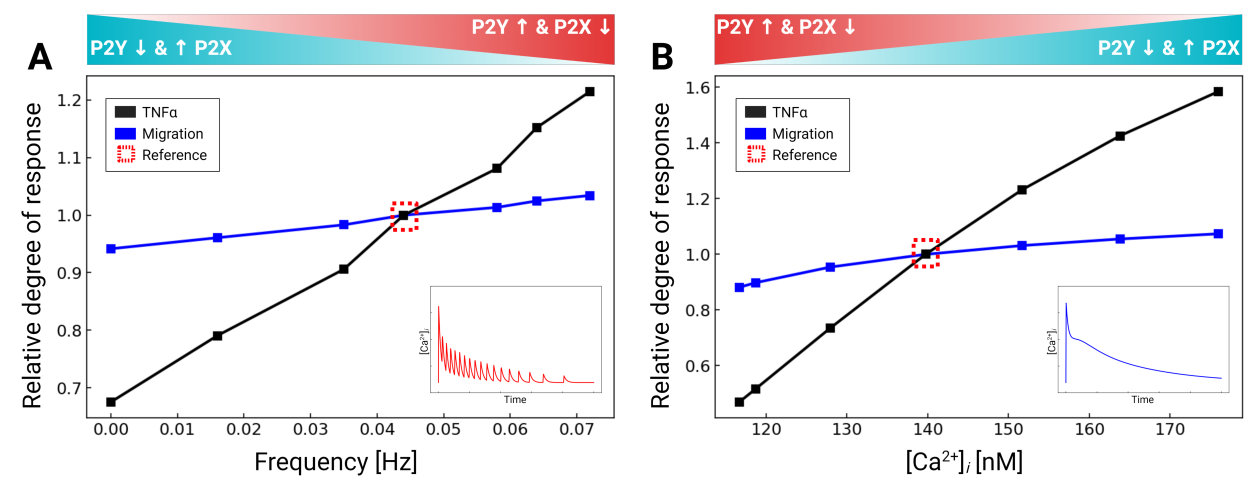

Figure 6: $\quad$ Predicted TNF $\alpha$ production (blue) and migration (black), normalized to control conditions (dashed box) in response to variations of the intracellular $\mathrm{Ca}^{2+}$ waveform frequency A) and amplitude B). All calculations were performed using $200 \mu \mathrm{M}$ ATP, and the data were collected at 5-min. 


\subsection{ATP-dependent responses in different microglia phe- notypes}

Microglia and their immortalized cell lines assume diverse phenotypes that are often characterized by differences in purinoreceptor expression $(30 ; 5 ; 15)$. We therefore tested how such changes in purinoreceptor expression influenced ATPtriggered $\mathrm{Ca}^{2+}$ waveforms and $\mathrm{Ca}^{2+}$-dependent functions. Although mRNA expression levels do not necessarily directly correlate with protein expression (21), as a first approximation we proportionately rescaled the purinergic receptor responses in our model according to the relative change in mRNA expression (see Table 1). We adjusted P2 contributions in our model in accordance with mRNA data sets published for P2X4, P2X7, P2Y2 and P2Y12 (see Fig. 7) in primary relative to BV2 microglial cells (30). Those data reflect 5-fold and 2fold reductions in $P 2 X 4$ and $P 2 X 7$ mRNA relative to primary cells, no change in P2Y2, and a near complete elimination of P2Y12 mRNA.

Table 1: Relative expression of P2 receptors in acutely isolated, primary cultured microglia, and BV2 cells in relative scale. Reported receptor mRNA expression is normalized to the expression level (mRNA count) found in primary cultured microglia and are incorporated in our model as scaling factors for receptor concentration $\left(\rho_{P 2 X 4}, \rho_{P 2 X 7}, \rho_{P 2 Y c}\right.$, and $\left.\rho_{P 2 Y 12}\right)$. *The mRNA expression was acquired from the comparison between cultured mouse microglia and BV2 cells $(30)$.

\begin{tabular}{ccc}
\hline \multirow{2}{*}{ Receptors } & \multicolumn{2}{c}{ mRNA Expression } \\
\cline { 2 - 3 } & Primary & BV2 $^{*}$ \\
\hline$P 2 X 4$ & $1 \times$ & $0.18 \times$ \\
$P 2 X 7$ & $1 \times$ & $0.65 \times$ \\
$\mathrm{P} 2 \mathrm{Y} 2$ & $1 \times$ & $1.02 \times$ \\
$\mathrm{P} 2 \mathrm{Y} 12$ & $1 \times$ & $0.030 \times$ \\
\hline
\end{tabular}

\subsubsection{BV2 $\mathrm{Ca}^{2+}$ transients}

Based on the adjusted $\mathrm{P} 2$ responses, and without any additional fitting, we predicted $\mathrm{Ca}^{2+}$ transients in response to 50-500 $\mu \mathrm{M}$ ATP treatment applied for 10 mins (Fig. 7). The model demonstrated that the reduced $P 2 X$ expression implied for BV2 cells resulted in moderately smaller $\mathrm{Ca}^{2+}$ transients relative to primary cells. The largest reductions were predicted at 50 and $100 \mathrm{uM}$, which was consistent with the preferential activation of $P 2 X 4$ with micromolar ATP and the channel's five-fold reduction in mRNA versus primary microglia. In contrast, modest reductions of $15 \%$ in $\mathrm{Ca}^{2+}$ transients after 20 seconds were predicted at $500 \mu \mathrm{M}$, which was inline with the $P 2 X 7$ channel's $35 \%$ reduction in P2X7 mRNA expression. Oscillations stemming from P2Y2 activation were predicted in the BV2 line and commensurate with those from primary cells. Importantly, the model confirms the intuitive result that $\mathrm{BV} 2 \mathrm{Ca}^{2+}$ transient amplitudes were reduced in a manner consistent with 5- and 2-fold reductions in $P 2 X 4$ and $P 2 X 7$ mRNA. 
A
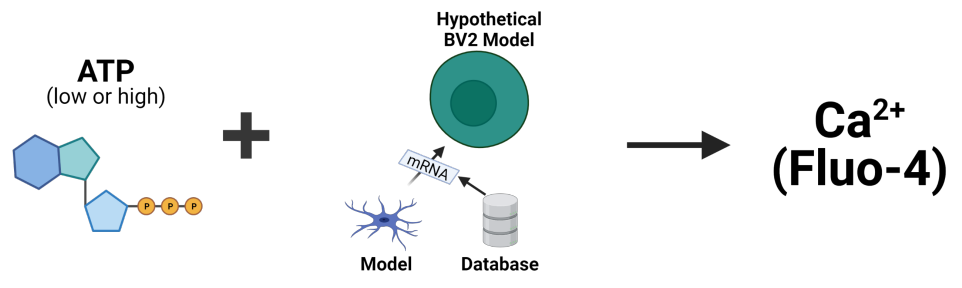

B
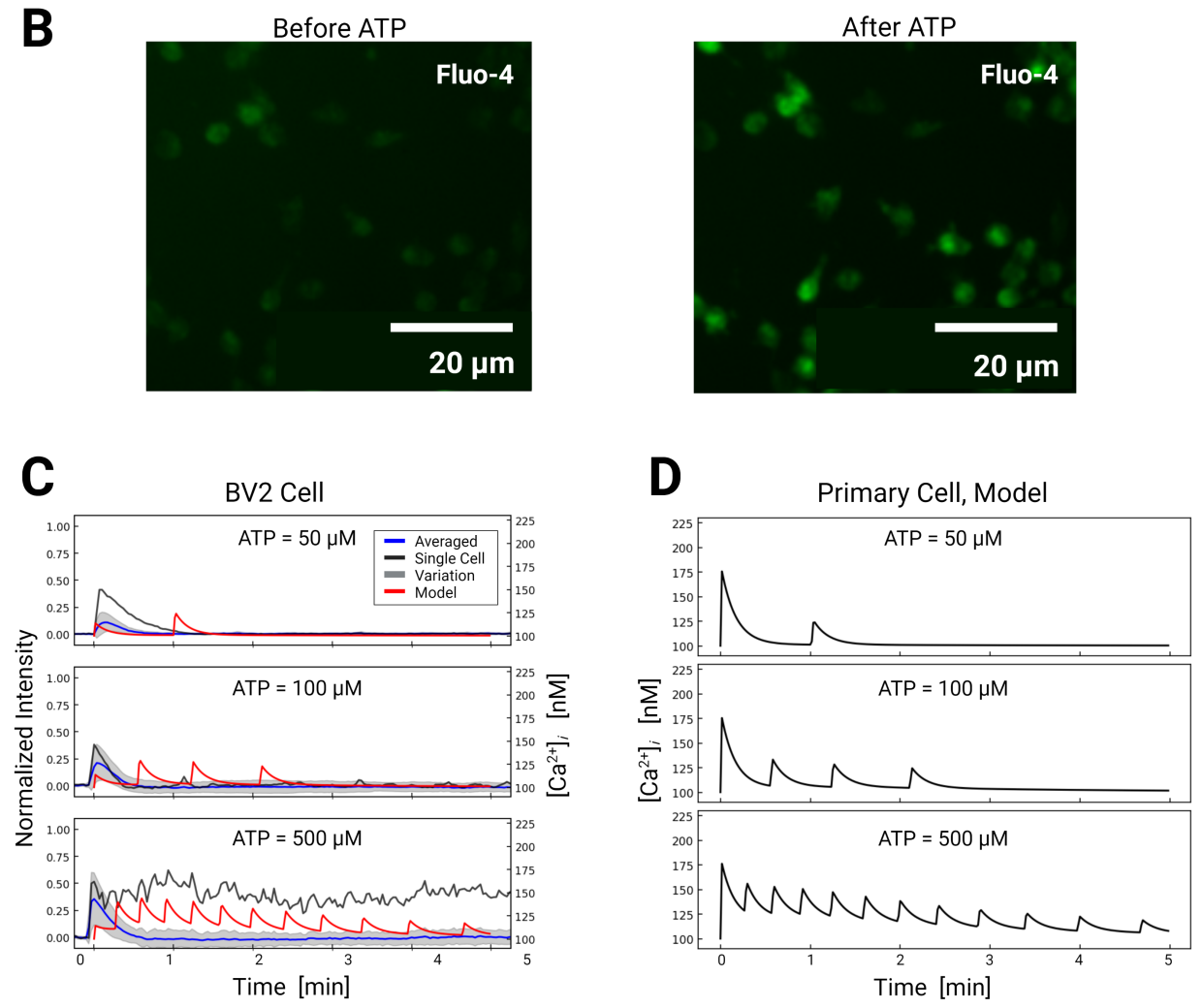

Figure 7: $\quad$ A) Schematic of ATP-induced $\mathrm{Ca}^{2+}$ transients in model BV2 cells assuming P2 expression levels inferred from BV2 cell mRNA (30). B) $\mathrm{Ca}^{2+}$ transients measured in BV2 microglia just before and after ATP treatment. C) Experimentally measured (blue) and predicted (red) $\mathrm{Ca}^{2+}$ transients from BV2 microglia. The shaded area represents the variation in signals measured in all cells. Oscillatory calcium signals were observed and a representative example of which is reported for each ATP dose (black). Transients recorded in each cell are reported in Fig. S12. D) Predicted transients in primary microglia for comparison. . 
To validate these model predictions, we measured $\mathrm{Ca}^{2+}$ transients in cultured BV-2 cells. Because we did not have calibrated BV2 $\mathrm{Ca}^{2+}$ data, we assumed the peak $\mathrm{Ca}^{2+}$ amplitudes at $50 \mu \mathrm{M}$ were approximately $112 \mathrm{nM}$ in amplitude to be consistent with the $82 \%$ reduction $P 2 X 4 \mathrm{mRNA}$. We report in Fig. 7 the average $\mathrm{Ca}^{2+}$ transients (black) for the BV cells, while the cell-to-cell variance in represented by a gray shaded region. We found that the initial phase $(<2 \mathrm{~min})$ of the predicted $\mathrm{Ca}^{2+}$ transients at 100 and $500 \mathrm{uM}$ were in strong agreement with the experimental data. However, the cell-tocell average did not exhibit fluctuations predicted by our model. Given that the mRNA data suggested similar P2Y2 expression in BV2 cells compared to primary cells, the model disagreement suggests that either ATP availability (as controlled by ectonucleotidase activity) or components of the $\mathrm{IP}_{3} \mathrm{Ca}^{2+}$ signaling pathway may be attenuated. We were unable to evaluate this assumption as mRNA data were not available for the corresponding proteins. Interestingly, we included for reference experimentally-measured $\mathrm{Ca}^{2+}$ 'outliers' (blue) that strongly diverged from the population average and exhibited weak $\mathrm{Ca}^{2+} \mathrm{os}^{-}$ cillations, which suggested that a subset of the cells had intact oscillatory $I P_{3}$ signaling. Overall, it was evident from our model predictions that the expression differences in P2X channel mRNA were sufficient to reproduce the initial phase of the experimentally-measured $\mathrm{Ca}^{2+}$ transients and capture $\mathrm{Ca}^{2+}$ oscillations evident in a subset of BV2 cells. However, additional measurements of protein mRNA or expression levels of P2Y2 or downstream targets would ultimately be necessary to align the model predictions with experimental observations.

\subsubsection{BV2 migration}

We last predicted BV2 migration upon 5 min ATP treatment intervals, based on the assumptions of reduced $P 2 X$ and $P 2 Y 12$ expression (see Fig. 8). In accordance with the reduced $P 2 Y 12$ mRNA measured in BV2 cells, across all ATP concentrations we predicted a nearly $70 \%$ reduction in migration relative to primary cells. This reduction was consistent with the P2Y 12 knock-out data reported by Ohsawa et althat demonstrated reduced, but not entirely eliminated, migration in primary microglia. The predicted distances monotonically increased with higher concentrations of applied ATP, which was consistent with the $\mathrm{Ca}^{2+}$ dependency in migration exemplified in Fig. 6.

To validate these predictions, we examined subsets of BV2 cells that exhibited linear extensions of their membrane akin to the cellular processes evident in branched microglia (shown in Fig. 8B). We found that these cells rapidly contracted upon ATP treatment, as exemplified in Fig. 8, but otherwise we did not observe appreciable directed migration over the data collection interval. We there defined this motility as the displacement of plasma membrane following ATP treatment. To assess ATP-dose dependencies for these responses, we measured the displacement of these extensions along manually-defined vectors. We report in Fig. $8 \mathrm{C}$ that maximum displacement distance of $1.6 \times 10^{1} \mathrm{\mu m}$ were evident in response to $500 \mathrm{\mu m}$ ATP, . Further, the dose-dependent displacement rates were consistent with the migration distances we predicted for BV2 cells in Fig. 8. Although these displacements were only reflected in a minority of the imaged cells, we found that morphological changes, surface ruffling and minor displacements of the cell somas were evident in a larger number of cells by visual inspection. These effects were more prominent for ATP-treated cells than those treated with saline $(\mathrm{ATP}=0 \mathrm{uM})$. Overall, our quantitative and qualitative assessments of BV2 motility were consistent with data from Zhang et al(91) that demonstrated BV2 cells exhibit a two-fold migration 'index' after 
bioRxiv preprint doi: https://doi.org/10.1101/2021.06.19.448892; this version posted June 22, 2021. The copyright holder for this preprint (which was not certified by peer review) is the author/funder. All rights reserved. No reuse allowed without permission.

24 hours when subject to ATP relative to to control conditions . 
A

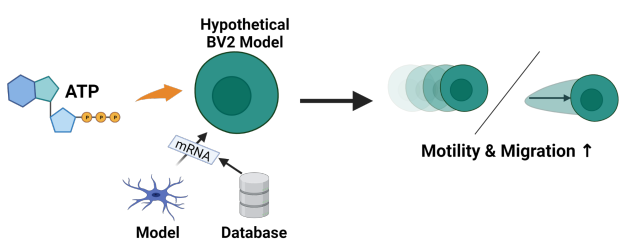

B
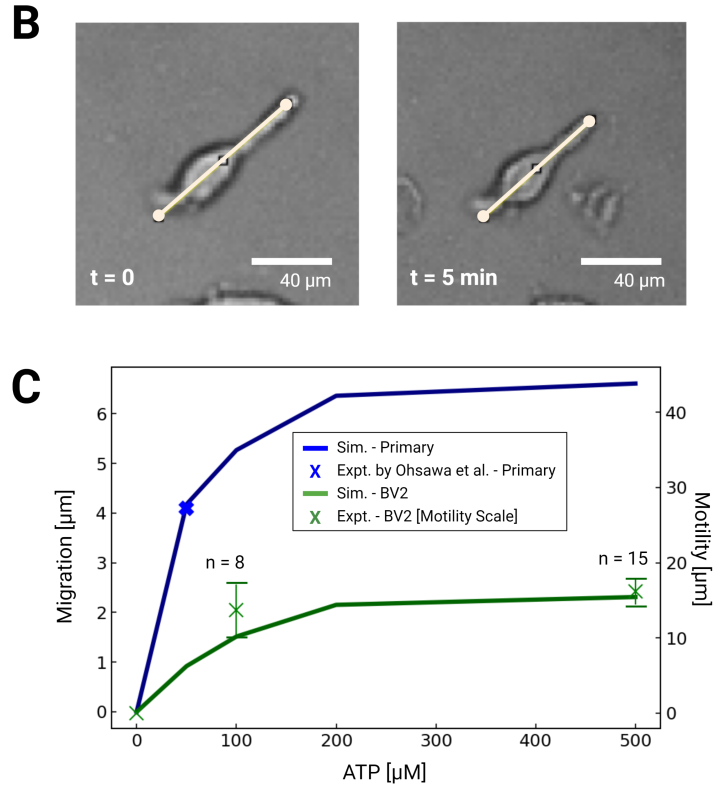

Figure 8: $\quad$ A) Schematic of predicted migration or motility in primary microglial cells or cells with P2 expression estimated from BV2 cell mRNA (30). B) Bright field image demonstrating ATP-dependent motility of microglial cell membrane (100 uM ATP at 5 minutes) C) Predicted (lines) migration or motility distance following 5 minute ATP treatment (0-500 uM) in primary microglia (blue) and BV2 cells (green). Experimental data in primary cells from Ohsawa et al and measured in BV2 cells are shown by blue and green X's, respectively, where the bars represent standard error . see notes below 


\section{Discussion}

\subsection{Findings of this paper}

In this study we used computational modeling to investigate how P2X and P2Y receptors collectively regulate $\mathrm{Ca}^{2+}$ and migration in microglia. These simulations indicate that $P 2 X$ and $P 2 Y$ encode $\mathrm{Ca}^{2+}$ signal waveforms that can selectively promote migration versus TNF $\alpha$ responses to ATP. This investigation necessitated extending a computational model of ionotropic $P 2 X$ receptor activation (9) to incorporate contributions from metabotropic $P 2 Y$ receptor activation. A schematic of the resulting model is shown in Fig. 9. With this model, we examined how the $\mathrm{Ca}^{2+}$ waveform from $P 2 Y$ receptors differ from those generated via ionotropic means, how $\mathrm{Ca}^{2+}$ transient waveforms influence migration and TNFa responses, how those processes are shaped by the relative activity of $P 2 X$ and $P 2 Y$ receptors, as well as nucleotidases, and how purinergic receptor mRNA data could be used to extrapolate the model to other microglial cell phenotypes. 


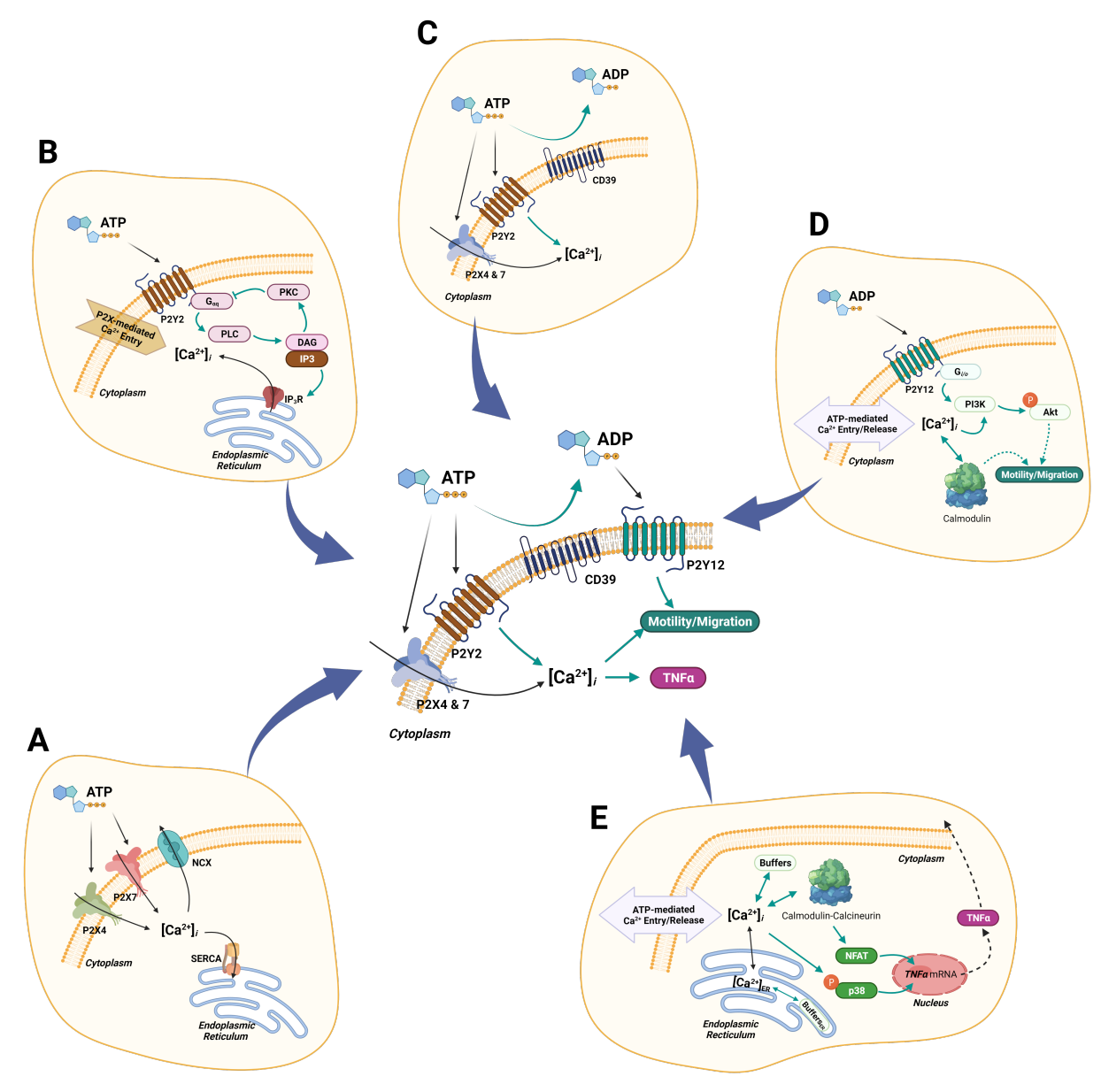

Figure 9: $\quad$ Complete schematic of the computational model. A) P2X4/7mediated $\mathrm{Ca}^{2+}$ entry. B) P2Y2-mediated $\mathrm{Ca}^{2+}$ transients. C) Hydrolysis of ATP by ENTs (CD39). D) P2Y12-mediated cell migration/motility. E) $\mathrm{Ca}^{2+}$ dependent downstream cascades associated with $\mathrm{TNF} \alpha$ production. . 


\subsection{Purinergic receptors and ectonucleotidases collectively control microglial $\mathrm{Ca}^{2+}$ waveforms}

Our first goal was to determine the extent to which highly-expressed P2 receptors in microglia shaped the waveform of intracellular $\mathrm{Ca}^{2+}$ signals in response to ATP. Indeed, our model indicated that metabotropic P2Y receptors contribute significantly to ATP-induced $\mathrm{Ca}^{2+}$ signals in microglia. Since in vivo microglia typically express high levels of $P 2 Y$ receptors (14), this further suggests that ER $\mathrm{Ca}^{2+}$ release may play a more significant role in tissue microglia than would be observed in ex vivo cultured microglia that are more commonly studied. Further, unlike the $\mathrm{P} 2 \mathrm{X}$ receptors that generally present high-amplitude, singlepeak $\mathrm{Ca}^{2+}$ waveforms, we show that $\mathrm{P} 2 \mathrm{Y}$ receptors can adopt oscillatory or transient, single-peak, $\mathrm{Ca}^{2+}$ fluctuations (shown in Fig. S3). Given that sustained increases in basal intracellular $\mathrm{Ca}^{2+}$ levels are associated with pathological states $(81 ; 34)$ and spontaneous oscillations are typical of homeostatic cells (42; 34), the balance of P2X versus P2Y contributions likely helps determine or at least indicate the cell phenotype (Fig. 10). Additionally, the ability for P2Y to encode diverse oscillatory and nonoscillatory signals could serve as a mechanism for controlling $\mathrm{Ca}^{2+}$-dependent functions in microglia. Our speculation is consistent with findings in other Eukaryotic cells that the dynamic profiles of $\mathrm{Ca}^{2+}$ waveforms tune cellular outcomes (69). As examples, oscillatory $\mathrm{Ca}^{2+}$ waves in oocytes are observed during in fertilization, while the timing of $\mathrm{Ca}^{2+}$ pulses in cardiac myocytes can selectively activate rapid CaMKII- versus slow NFAT-mediated gene responses (89).

Our simulations indicate that the activity of proteins belonging to the $G_{\alpha q} / I P_{3}$ pathway determine whether $P 2 Y$ receptors generate single, long duration peaks or oscillations. P2Y receptors are G protein coupled receptor (GPCR)s, of which P2Y2 promote $I P_{3}$-dependent ER $\mathrm{Ca}^{2+}$ release via activating $G_{\alpha q}$ proteins $(42)$. This pathway includes PKC-dependent negative-feedback inhibition of $G_{\alpha q}$, which gives rise to stable $I P_{3}$ oscillations and periodic intracellular $\mathrm{Ca}^{2+}$ release (68). Negative feedback inhibition is a property of classical biochemical oscillators, for which the enzyme reaction rates determine the periodicity and decay of products like $I P_{3}(82)$, Although these oscillations may be stochastic, deterministic representations $(82 ; 70)$ amenable to ordinary differential equation modeling are commonly used, given their ability to approximate the amplitude and peak-to-peak intervals of experimentally-measured $\mathrm{Ca}^{2+}$ release events (7). By modulating parameters like $k g_{p 2 y}$, which controls the activation of $G_{\alpha q}$ in our model, we identified how $I P_{3}$ generation can be scaled to yield oscillatory versus single-peak waveforms commonly observed in microglia. Since these parameters represent the activity of proteins composing the $I P_{3}$ synthesis pathways, waveforms exhibited in microglia are expected to be inherently sensitive to factors such as protein expression and co-localization (41).

Our simulations strongly implicate the role of ectonucleotidase (ENT) activity in controlling the responsiveness of microglia to extracellular ATP and related nucleotides. We demonstrate that neglecting ectonucleotidase activity in our model yielded sustained $\mathrm{Ca}^{2+}$ oscillations that were inconsistent with measurements in microglia cells and namely the data collected by Ikeda et al for MG5 microglial cells. This therefore suggests that ectonucleotidase activity determines the duration of ATP-mediated $\mathrm{Ca}^{2+}$ waveforms in microglia and ultimately cellular responses like migration and cytokine production. The ectonucleotidases CD39 and CD73 are the most highly expressed nucleotidases in microglia (50). CD39 rapidly hydrolyzes ATP and ADP into AMP, which 
curtailed $\mathrm{Ca}^{2+}$ waveforms within minutes of ATP treatment in our simulations. While our model of CD39 activity was parameterized to fit data from Robson et al(62), more detailed models such as from Sandefur et al(63) could give additional insights into how other expressed ectonucleotidases influence microglial responses to ATP. As an example, augmenting the CD39 model with contributions from the CD73 ectonucleotidase isoform(92), which metabolizes AMP into adenosine, will help determine which adenine metabolites predominate at the cell surface (61), as well as the receptors they stimulate.

Interestingly, it is increasingly recognized that extensions of the microglia plasma membrane infiltrate neural synapses which may be implicated in how glia scale and pruning neuron junctions Check this out: https://www.nature.com/articles/s41467018-03566-5. ATP can be intermittently released in these junctions $(62 ; 29)$, therefore we expect that the timescale and amplitude of those release events, as well as the rate by which ATP is metabolized, will control how microglia respond to these intercellular signals to fulfill their homeostatic functions. Here, spatially-explicit models of nucleotidases(61) that predict local ATP pools between interfaced cells could be important for determining how microglial responses in multi-cellular assemblies such as neural synapses differ from in vitro preparations.

\subsection{Purinoreceptors control microglia migration and motil- ity}

Our study contributes a quantitative model linking P2Y12 activation to the PI3K and Akt axis that is essential for microglia migration $(58 ; 36 ; 59)$. Unlike the metabotropic $P 2 Y$ receptors implicated in intracellular $\mathrm{Ca}^{2+}$ signals, P2Y 12 activates $G_{i / o}$, which directly stimulates PI3K and its phosphorylation of Akt. Our model reproduces the rate of PI3K-dependent Akt phosphorylation in addition to migration distances inferred from Ohsawa et al(58). Interestingly, both our model and data from Ohsawa et al(58) suggest that Akt phosphorylation is slow and reaches its maximum about three minutes after ATP treatment. This contrasts with the rapid onset of migration observed by others $(19 ; 22)$. For instance, supplemental movies from Dou et al(19) indicate that microglia migrate almost immediately in response to ATP and approach a rate of $[1.7$ $\mathrm{um} / \mathrm{s}$ ] within $10 \mathrm{~min}$ of $1 \mathrm{mM}$ ATP. Similar findings for microglia in tissue slices were also reported (22). Hence, either low levels of phosphorlylated Akt are sufficient for invoking migration at early timepoints, or alternatively, P2Y12or $p$ Akt-independent mechanisms mediate the rapid onset of migration. In support of the latter speculation, our model and experiments from Ohsawa et al(58) demonstrate that P2Y12 knock-out dramatically reduces, but does not eliminate, migration.

Given observations suggesting that 1) P2Y12 KO microglia migrate and 2) extracellular $\mathrm{Ca}^{2+}$ significantly enhances migration by promoting Akt phosphorylation $(58 ; 59)$, our model was constructed to reflect the $\mathrm{Ca}^{2+}$-dependence of microglial migration. Importantly, our simulation results indicate that migration is significantly reduced when P2X contributions are neglected, in accordance with Ohsawa et al $(58 ; 59)$. This finding suggests that there are ATP-triggered, $\mathrm{Ca}^{2+}$-dependent migration mechanisms $(58 ; 36 ; 59)$ that could be sensitive to rapid $\mathrm{Ca}^{2+}$ signals, such as those exhibited by P2X4. These mechanisms could include $\mathrm{Ca}^{2+}$-dependent recruitment of PI3K to the plasma membrane (58), activation of the $\mathrm{Ca}^{2+}$-binding protein Iba (37), regulation of cytoskeletal proteins (48), and regulation of myosin by the CaM-dependent 
myosin light-chain kinase (66). To our knowledge, the rates of these mechanisms have not been examined in microglia, which precluded us from explicitly representing these processes in our model. However, we postulate that $P 2 X$ receptors trigger $\mathrm{Ca}^{2+}$-dependent migration machinery that initiate migration, after which the gradual activation of the PI3K/Akt axis via P2Y12 sustains migration over longer time intervals. Along these lines, low-amplitude $\mathrm{Ca}^{2+}$ oscillations from metabotropic P2Y receptors likely enhance migration, which is consistent with the requirement of $I P_{3}$ induced $\mathrm{Ca}^{2+}$ release for P2Y12-driven chemotaxis (Kettenmann review (42). Clearly, ATP-induced migration in microglia is exceedingly complex (reviewed in $(10 ; 73)$ ) and warrants further investigation to unravel the intricate relationships between $\mathrm{Ca}^{2+}$ dynamics and migration.

Our simulations implicate $\mathrm{Ca}^{2+}$ signaling in promoting migration as well as TNF $\alpha$ synthesis. This raises the question as to whether ATP can stimulate microglia migration and motility associated with homeostatic functions ithout driving inflammatory cytokine responses. It is apparent from our simulations that a key distinction between these cellular responses is the duration of the intracellular $\mathrm{Ca}^{2+}$ waveform. Namely, our simulations show that submicromolar ATP treatments yield short-lived $\mathrm{Ca}^{2+}$ waveforms ( $<2$ minutes) that are nonetheless sufficient for migration. In contrast, we show that higher amplitude $\mathrm{Ca}^{2+}$ waveforms or diminished CD39 activity are necessary for generating appreciable TNF $\alpha$ responses. Blocking ectonucleotidase activity prolongs $P 2 Y$ and P2X $4 \mathrm{Ca}^{2+}$ transients and thereby increase TNF $\alpha$ mRNA production (Fig. S7). Similar prolonged $\mathrm{Ca}^{2+}$ signals are associated with inflammatory microglia $(42 ; 34)$ and are routinely induced via millimolar ATP treatment $P 2 X 7$, or reagents including LPS and ionomycin (34). It is apparent that the slow rate of activated transcription factor translocation into the nucleus which can occur over minutes (4) necessitates prolonged $\mathrm{Ca}^{2+}$ transients to induce transcription. This was reflected in our model for NFAT and was experimentally demonstrated for $\mathrm{Ca}^{2+}$ ionophore treated HEK293 cells in (4).

\subsection{Differential purinergic receptor expression and its im- pact on microglia function}

Our model suggests that the relative expression levels of P2 receptors enable microglia to regulate migration and pro-inflammatory responses to ATP (49). This occurs in part through modulating intracellular calcium dynamics. Since $P 2 X$ and $P 2 Y$ receptors exhibit unique and diverse $\mathrm{Ca}^{2+}$ waveforms (20), we hypothesized that phenotype-specific differences in $\mathrm{P} 2$ receptor expression in microglia influence both 1) $\mathrm{Ca}^{2+}$ responses and 2) migration. We investigated this hypothesis by adapting P2 expression levels in the model based on published BV2 cell mRNA data sets. Model predictions of ATP-stimulated $\mathrm{Ca}^{2+}$ waveforms and migration were compared against experiments with BV2 cells.

The mRNA data used for our model (30) indicated similar numbers of P2X4, P2X7, P2Y2 transcripts compared to primary cells. For simplicity, we assumed that the purinergic receptor activity in our model correlated with mRNA expression. However, data quantifying receptor expression and membrane localization is ultimately needed to accurately receptor activity. Nonetheless, based on our assumptions the model predicted $\mathrm{Ca}^{2+}$ waveforms in BV2 cells that were qualitatively similar to those simulated for primary cells. In contrast, P2Y12 mRNA transcripts were reduced 30-fold in BV2 cells relative to primary cells (30). Accordingly, our model predicted diminished migration in BV2 cells. We 

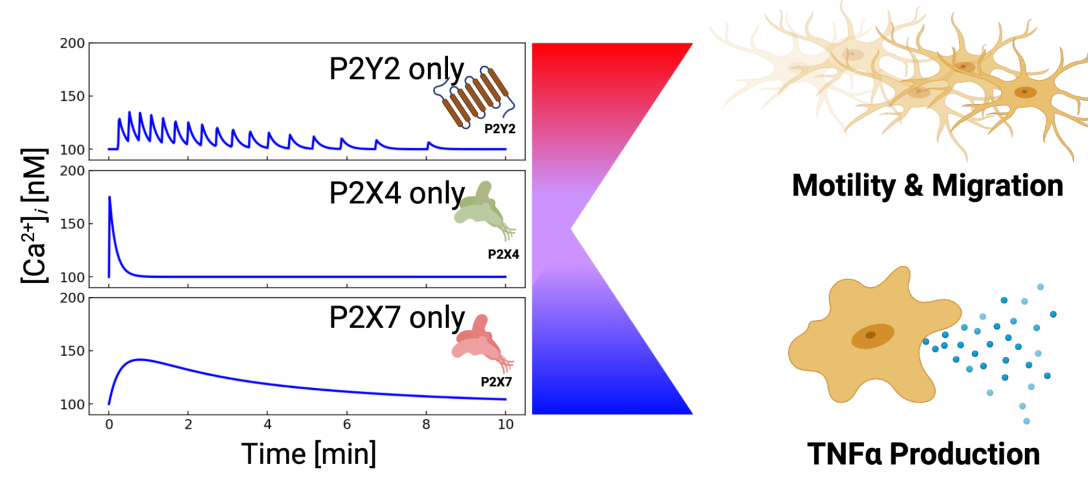

Figure 10: $\quad$ P2s can be combined to control different cellular outcomes. $P 2 X 4$-induced $\mathrm{Ca}^{2+}$ entry manifests a sharp but brief rise in cytosolic $\mathrm{Ca}^{2+}$. $P 2 X 7$-mediated $\mathrm{Ca}^{2+}$ entry results in blunt and prolonged $\mathrm{Ca}^{2+}$ elevations. $P 2 Y$-class receptors (mainly P2Y2) yield oscillatory $\mathrm{Ca}^{2+}$ transients .

did not observe directed migration in our BV2 cell assays, which is consisted with other reports that confirm negligible or very slow migration responses to chemotactic stimuli $(30 ; 24 ; 28)$ Nonetheless, we observed that the BV2 cells exhibited motility responses like membrane ruffling and membrane displacement in response to ATP. The motility processes increased in a ATP-dose dependent manner consistent with our model predictions for migration.

\section{$6 \quad$ Limitations}

There are several model limitations that can guide refinement in subsequent studies. A prominent limitation is that many of the underlying biological processes linking ATP binding to migration and cytokine responses are not completely resolved. Of those we considered in our model, the kinetics of those processes are also imprecise. The $\mathrm{Ca}^{2+}$ responses induced by the purinoreceptors are perhaps the best characterized of these processes, as time-dependent fluorescence data were available. Other processes though were heavily reliant on western blotting and microscopy, which are much less precise. We also assumed that the biochemical pathways are spatially homogeneous within the cell for the simplicity of modeling and parameterization. Nonetheless, a number of proteins have precise subcellular localization or undergo changes in a localization about activation, such as P2X4(78) and NFAT(4). Accounting for these changes could impact their ability to promote gene transcription versus motility or migration responses. Along these lines, for simplicity we considered only changes in P2 mRNA expression when extending our model to the BV2 microglial cells. Significant changes in other downstream proteins mediating migration responses would be expected to have an impact on migration.

It was evident from our measurements of ATP-induced $\mathrm{Ca}^{2+}$ waveforms that cell-to-cell variation in responses was substantial. Namely, many of the individual cells presented traces that strongly deviated from the mean (see Fig. 7) Our modeling approach relies on deterministic equations, which are most appropriate 
for describing the average behavior of a large ensemble of cells. This approach is valid, given that many of the experimental data used to train our approach were from western blots and mRNA quantification, which generally use large pools of cells. Stochastic models such as that from Skupin or Cao et al $(6 ; 68 ; 67)$ could be used in complement to our model to investigate how cell-to-cell variations in gene expression or protein activity could impact ATP-induced $\mathrm{Ca}^{2+}$ waveforms.

Similarly, our experimental measurements of BV2 yielded largely non-oscillatory waveforms. Nonetheless, stimulation of BV2 cells with ATP yielded oscillatory $\mathrm{Ca}^{2+}$ transients in a small subset of cells. This raises the possibility that this subset expresses $P 2 Y$ receptors at a greater level than the population average. Cell-to-cell variations in purinergic receptor transcripts or expression have not been characterized in BV2 cell lines, which limits our ability to associate oscillations in subsets of BV2 cells with P2X or P2Y activity. However, several single-cell RNAseq studies $(14 ; 15 ; 30)$ have been conducted for primary microglia cultures, which indicate there exist sub-populations with unique patterns of $P 2 X$ versus $P 2 Y$ receptor expression. At the very least, the cell-to-cell variability underscores a need for single-cell characterization of cell genotypes and phenotypes, as well as sensitivity analyses such as in Fig. 6 to better characterize $\mathrm{Ca}^{2+}$ waveforms and their effects in diverse microglial cell populations.

Lastly, our model could be improved by accounting for $K^{+}$-dependent signaling in particular. There are a multidude of mechanisms by which changes in intercellular $K^{+}$and membrane potential could influence microglial signal transduction, such as by enhancing the electromotive force for $\mathrm{Ca}^{2+}$ entry, or by influencing the activity of the sodium $/ K^{+}$ATPase. Reflecting these contributions may provide more complete descriptions of $K^{+}$mechanisms mediating inflammation (72) and migration (76). For instance, $P 2 Y 12$-dependent activation of $K^{+}$channel dynamics is believed to contribute to migration (42). This is supported by studies suggesting that $P 2 Y 12$-activation induces substantial outward current associated with $K^{+}$channel activity $(76 ; 23)$. It is further understood that $K^{+}$efflux constitutes an important stage of priming the microglial inflammasome, which is necessary for maturating pro-inflammatory cytokines such as IL-1 $\beta$ (84). Along these lines, it is increasingly recognized that P2X7 and P2X 4 conduct $K^{+}$countercurrent when activated $(55 ; 87)$; moreover, changes in $K^{+}$-channel expression upon microglial activation may contribute to these responses (54).

While we modeled PI3K, RAGE/RhoaA/ROCK are also involved in mediating chemotaxis $(77 ; 90)$. For instance, it was shown that inhibition of ROCK via $\mathrm{H}-1152$ reduced p38 phosphorylation and membrane ruffling following ATPdependent P2Y12/13 activation (77). p38 is known also to be $\mathrm{Ca}^{2+}$ sensitive (80), which again introduces aother potential pathway sensitive to $\mathrm{Ca}^{2+}$ waveform characteristics. Inhibition of MLCK, Rac1 and p38-MAPK also results in the attenuation of motility in primary cultured murine microglia(51). CaM dependent contributions to migration are also important to recognize. O'Brien et al found that active CaM was involved in chemotaxis by monitoring the activity of its target, phosphodiesterase (PDE1) (57). Similarly, Yao et al demonstrated the involvement of CaM in migration via CaM-dependent myosin light chain kinase (MLCK)(86). Altogether, the dependencies of cell migration on diverse signaling pathways suggest microglia are highly adaptive to a variety of extracellular stimuli to promote motility responses. Hence, resolving these interdependencies will warrant additional studies and their dependency on $\mathrm{Ca}^{2+}$ to delineate microglial migration responses specific to ATP. 


\section{Conclusions}

ATP-induced $\mathrm{Ca}^{2+}$ waveforms in microglia have diverse properties, such as amplitude, duration and oscillatory behavior. These properties depend on which P2 receptor types are activated, in addition to ectonucleotidase activity. In this study, we developed a computational model to predict how P2 receptors and ectonucleotidase hydrolases control $\mathrm{Ca}^{2+}$ waveforms in microglia that in turn influence microglia migration and cytokine production. With this model, we examine the propensity for these diverse $\mathrm{Ca}^{2+}$ waveforms to drive these canonical microglial responses to ATP.

We interpret these results in light of our previously published microglia model for probing P2X contributions to TNFa mRNA synthesis as a model for pro-inflammatory cytokine responses to ATP (9). In that study, we demonstrated that $\mathrm{Ca}^{2+}$ waveforms generated by P2X activation are typically highamplitude and of finite duration. With the addition of $P 2 Y$, we predict a wider diversity of $\mathrm{Ca}^{2+}$ waveforms that can include stable and damped oscillations of low amplitude and frequency. Interestingly, our modeling results highlight a complementary role of ectonucleotidase activity, namely CD39, in controlling the ATP pool available to trigger such responses, by hydrolyzing ATP and ADP into AMP. This finding is of particular importance, given that CD39 and a complementary ectonucleotidase, CD73, of which the latter hydrolyzes AMP and AMP into adenine, are highly expressed in microglia and undergo significant changes in expression (39).

Our simulations indicate that the distinct $\mathrm{Ca}^{2+}$ waveforms shaped by $\mathrm{P} 2$ receptors and CD39 selectivity control downfield signaling pathways. We investigated this selective control by simulating migration versus cytokine production responses as a function the $\mathrm{Ca}^{2+}$ waveforms generated by $\mathrm{P} 2$ receptors. Our model indicates that short-duration, oscillatory $\mathrm{Ca}^{2+}$ transients induced by $\mathrm{P} 2 \mathrm{Y}$ receptors and P2X4 with micromolar ATP are sufficient to promote migration responses without significantly inducing TNFa production. On the other hand, millimolar ATP concentrations that activated P2X7 supported sustained cytosolic $\mathrm{Ca}^{2+}$ levels that could trigger $\mathrm{TNF} \alpha$ release. We speculate that these findings illustrate how microglia orchestrate complex cytokine and migration functions in response to ATP as well as other damage associated molecular patterns.

The concerted roles of P2X, P2Y and ectonucleotidase proteins in mediating cellular responses to ATP further suggest how changes in gene expression shape microglia responses to stimuli. For instance, higher P2Y12 expression in resting relative to pro-inflammatory microglia likely favor migration responses to ATP in the former. Similarly, elevated P2X4 and P2X7 expression in proinflammatory microglia sensitize cytokine responses to ATP. These differences in microglia responses following changes in gene programming underscore the need for models to account for changes in protein activity.

Robust characterization of detailed signaling networks in diverse microglia phenotypes remains a significant challenge. This is especially challenging for tissue resident microglia that are difficult to experimentally manipulate in situ. For this reason, we tested if our model could leverage mRNA transcript data from the BV2 microglial cell line to approximate changes in $\mathrm{P} 2$ receptor activity. Using those mRNA data, we found that the model predicted $\mathrm{Ca}^{2+}$ waveforms and migration responses to ATP that were reasonably consistent with experiments we conducted using the BV2 microglia cell line. This raises the possibility that coupling models trained from cultured primary or immortalized cells in vitro with transcriptomic and proteomic data could enable predictions of microglia behavior in vivo, where extensive functional testing is not feasible. Related to 
this, since dysfunctional microglial responses are associated with neurological disorders including chronic pain, Alzheimer's Disease and Parkinson's Diseases (12), our computational model may be an invaluable tool to probe mechanisms underlying these diseases.

\section{Acknowledgements}

Research reported in this publication was supported by the Maximizing Investigators' Research Award (MIRA) (R35) from the National Institute of General Medical Sciences (NIGMS) of the National Institutes of Health (NIH) under grant number R35GM124977. This work used the Extreme Science and Engineering Discovery Environment (XSEDE)(79), which is supported by National Science Foundation grant number ACI-1548562. All the figures are processed or adapted from BioRender.com.

\section{Supplement}

\section{S.1 Tables}


Table S1: Reactions used in the computational microglia model.

\begin{tabular}{llll}
\hline Rxn No. & Rxn & Cell & Reference \\
\hline 1 & $\mathrm{P} 2 \mathrm{Y} \Rightarrow I P_{3} \Rightarrow\left[\mathrm{Ca}^{2+}\right]_{i}$ & heptaocyte & $(16)$ \\
2 & $P 2 X 4 \Rightarrow\left[\mathrm{Ca}^{2+}\right]_{i}$ & microglia & $(78 ; 26)$ \\
3 & $P 2 X 7 \Rightarrow\left[\mathrm{Ca}^{2+}\right]_{i}$ & microglia & $(44 ; 8)$ \\
4 & {$\left[\mathrm{Ca}^{2+}\right]_{e} \Rightarrow\left[\mathrm{Ca}^{2+}\right]_{i}($ leak $)$} & & Fit \\
5 & $\mathrm{NCX} \Rightarrow\left[\mathrm{Ca}^{2+}\right]_{e}$ & microglia & $(65)$ \\
6 & {$\left[\mathrm{Ca}^{2+}\right]_{i} \Rightarrow \mathrm{Buffers}$} & & Fit \\
7 & {$\left[\mathrm{Ca}^{2+}\right]_{i} \Rightarrow \mathrm{CaM} \Rightarrow \mathrm{CN}$} & Cardiac & $(31 ; 4)$ \\
8 & {$\left[\mathrm{Ca}^{2+}\right]_{i} \Rightarrow \mathrm{SERCA}$} & Cardiac & $(65)$ \\
9 & {$\left[\mathrm{Ca}^{2+}\right]_{E R} \Rightarrow\left[\mathrm{Ca}{ }^{2+}\right]_{i}($ leak $)$} & & Fit \\
10 & {$\left[\mathrm{Ca}^{2+}\right]_{E R} \Rightarrow \mathrm{Calreticulin}(\mathrm{Calsequestrin})$} & astrocytes & $(65)$ \\
$11 \mathrm{a}$ & {$\left[\mathrm{Ca}{ }^{2+}\right]_{i} \Rightarrow \mathrm{p}-\mathrm{p} 38$} & microglia & $(80)$ \\
$11 \mathrm{~b}$ & $\mathrm{p}-\mathrm{p} 38 \Rightarrow \mathrm{TNF} \alpha$ & microglia & $(33)$ \\
$12 \mathrm{a}$ & $\mathrm{CN} \Rightarrow \mathrm{NFAT}$ & microglia & $(88 ; 13)$ \\
$12 \mathrm{~b}$ & NFAT cycle & myocyte & $(13)$ \\
$12 \mathrm{c}$ & NFAT $\Rightarrow \mathrm{TNF} \alpha$ & microglia & $(53)$ \\
13 & $\mathrm{TNF} \alpha$ Production & microglia & Fit \\
14 & Activation of $P 2 X 7 \Rightarrow$ TNF $\alpha$ release & microglia & $(3)$ \\
15 & $P 2 Y 12 \Rightarrow G_{i / o}$ & microglia & $(42 ; 59)$ \\
16,17 & $G_{i} / o \Rightarrow$ PI3K $\Rightarrow$ pAkt & microglia & $(59 ; 23)$ \\
18 & $\mathrm{pAkt}+\left[\mathrm{Ca}{ }^{2+}\right]_{i} \Rightarrow$ Migration & microglia & $(59)$ \\
19 & NTPDase of ATP & COS-7 & $(47 ; 62)$ \\
\hline
\end{tabular}

Table S2: General Parameters

\begin{tabular}{|c|c|c|}
\hline Parameters & Values & Units \\
\hline $\mathrm{T}$ & 310 & $\mathrm{~K}$ \\
\hline$V_{p o t}$ & $-5.0 \times 10^{-2}$ & V \\
\hline $\mathrm{F}$ & 96485.332 & $\frac{C}{m o l}$ \\
\hline $\mathrm{R}$ & 8.314 & $\frac{J}{m o l \times K}$ \\
\hline$r_{\text {microglia }}$ & 3.68 & $\mu m$ \\
\hline$\left[\mathrm{Ca}^{2+}\right]_{e}$ & 2 & $\mathrm{mM}$ \\
\hline$\left[\mathrm{Na}^{+}\right]_{e}$ & 145 & $\mathrm{mM}$ \\
\hline$\left[\mathrm{Na}^{+}\right]_{i}$ & 8 & $\mathrm{mM}$ \\
\hline
\end{tabular}


Table S3: Parameters associated with S.2.2

\begin{tabular}{lll}
\hline Parameters & Values & Units \\
\hline$k d_{P 2 Y}$ & 410.0 & $\mathrm{nM} / \mathrm{s}$ \\
$h d_{P 2 Y}$ & 4.0 & $1 / \mathrm{s}$ \\
$l d_{P 2 Y}$ & 0.3 & $\mathrm{nM} / \mathrm{s}$ \\
$k c_{P 2 Y}$ & $1.5 \times 10^{6}$ & $\mathrm{nM} / \mathrm{s}$ \\
$k_{\text {rec }, P 2 Y}$ & 0.01 & $1 / \mathrm{s}$ \\
$h_{\text {rec }, P 2 Y}$ & 10.0 & $1 / \mathrm{s}$ \\
$K p_{P 2 Y}$ & 20.0 & $1 / \mathrm{s}$ \\
$K c_{P 2 Y}$ & 100.0 & $1 / \mathrm{s}$ \\
$K g_{P 2 Y}$ & 50.0 & $\mathrm{nM}$ \\
$K d_{P 2 Y}$ & 5.0 & $\mathrm{nM}$ \\
$K s_{P 2 Y}$ & 5.0 & $\mathrm{nM}$ \\
{$[P H]$} & 0.0 & $\mathrm{nM}$ \\
$k a_{P 2 Y}$ & 1000.0 & $\mathrm{nM}$ \\
$n_{C a^{2+}, P 2 Y}$ & 3.0 & \\
{$[P 2 Y]_{\text {total }}$} & 200.0 & $\mathrm{nM}$ \\
$G_{\alpha, t o t a l}$ & 200.0 & $\mathrm{nM}$ \\
$n_{P 2 Y}$ & 2.0 & \\
$m_{P 2 Y}$ & 4.0 & \\
$K d_{\text {ATP }, P 2 Y}$ & 250.0 & $\mu \mathrm{M}$ \\
$K_{\text {deg, } P 2 Y}$ & 0.1 & $1 / \mathrm{s}$ \\
\hline
\end{tabular}

Table S4: Parameters associated with $P 2 X 4$ receptor kinetics (S.2.3)

\begin{tabular}{lll}
\hline Parameters & Values & Units \\
\hline$k_{1}$ & 1.0 & $1 / \mathrm{s}$ \\
$k_{2}$ & $2.61 \times 10^{5}$ & $1 /(\mathrm{M} \times \mathrm{s})$ \\
$k_{3}$ & 0.1 & $1 / \mathrm{s}$ \\
$k_{4}$ & $1.6 \times 10^{5}$ & $1 /(\mathrm{M} \times \mathrm{s})$ \\
$k_{5}$ & 0.25 & $1 / \mathrm{s}$ \\
$k_{6}$ & $8.0 \times 10^{6}$ & $1 /(\mathrm{M} \times \mathrm{s})$ \\
$H_{1}$ & 0.02 & $1 / \mathrm{s}$ \\
$H_{2}$ & 0.0 & $1 / \mathrm{s}$ \\
$H_{6}$ & 0.1 & $1 / \mathrm{s}$ \\
\hline
\end{tabular}


Table S5: Parameters associated with $P 2 X 7$ receptor kinetics (S.2.3)

\begin{tabular}{lll}
\hline Parameters & Values & Units \\
\hline$k_{1}$ & 190 & $1 / \mathrm{s}$ \\
$k_{2}$ & $8.13 \times 10^{3}$ & $1 /(\mathrm{M} \times \mathrm{s})$ \\
$k_{3}$ & 0.04 & $1 / \mathrm{s}$ \\
$k_{5}$ & 0.07 & $1 / \mathrm{s}$ \\
$H_{1}$ & $5.0 \times 10^{-3}$ & $1 / \mathrm{s}$ \\
$H_{2}$ & 0.3 & $1 / \mathrm{s}$ \\
$H_{5}$ & 0.0 & $1 / \mathrm{s}$ \\
$H_{6}$ & 0.0 & $1 / \mathrm{s}$ \\
$k_{4, \text { low }}$ & $1.0 \times 10^{2}$ & $1 /(\mathrm{M} \times \mathrm{s})$ \\
$k_{6, \text { low }}$ & $5.0 \times 10^{2}$ & $1 /(\mathrm{M} \times \mathrm{s})$ \\
$H_{7, \text { low }}$ & $1.0 \times 10^{3}$ & $1 / \mathrm{s}$ \\
$k_{4, \text { high }}$ & $7.0 \times 10^{3}$ & $1 /(\mathrm{M} \times \mathrm{s})$ \\
$k_{6, \text { high }}$ & 0.1 & $1 /(\mathrm{M} \times \mathrm{s})$ \\
$H_{7, \text { high }}$ & 0.008 & $1 / \mathrm{s}$ \\
$k_{d}$ & 420 & $\mu M$ \\
$n$ & 15 & \\
\hline
\end{tabular}

Table S6: Parameters associated with the estimation of inward current and corresponding $\mathrm{Ca}^{2+}$ influx (S.2.3)

\begin{tabular}{lll}
\hline Parameters & Values & Units \\
\hline$G_{12, P 2 X 4}$ & $6.15 \times 10^{-10}$ & $\frac{C}{s \times V}$ \\
$G_{12, P 2 X 7}$ & $1.0 \times 10^{-8}$ & $\frac{C}{s \times V}$ \\
$E_{12, P 2 X 4}$ & 0.0 & $\mathrm{~V}$ \\
$E_{12, P 2 X 7}$ & 0.0 & $\mathrm{~V}$ \\
$f_{I_{C a^{2+}, P 2 X 4}}$ & 0.0824 & \\
$f_{I_{C a^{2+}, P 2 X 7}}$ & 0.1 & \\
$f_{\text {conv. } P 2 X 4}$ & 11 & \\
$f_{\text {conv. }, P 2 X 7}$ & 1 & \\
\hline
\end{tabular}


Table S7: Parameters for NCX mechanisms associated with S.2.4

\begin{tabular}{lll}
\hline Parameters & Values & Units \\
\hline$Q_{10}$ & 1.20 & \\
$K d_{A c t}$ & 40.0 & $\mathrm{nM}$ \\
$n_{H}$ & 3.44 & \\
$H_{N a}$ & 3.60 & \\
$V_{\max }$ & 35 & $\mathrm{~A} / \mathrm{F}$ \\
$\eta$ & 0.70 & \\
$k_{\text {sat }}$ & 0.04 & \\
$K_{\max ,\left[\mathrm{Ca}^{2+}\right]_{i}}$ & $3.63 \times 10^{3}$ & $\mathrm{nM}$ \\
$K_{\max ,\left[\mathrm{Na}^{+}\right]_{i}}$ & $1.23 \times 10^{7}$ & $\mathrm{nM}$ \\
$K_{\max ,\left[\mathrm{Na}^{+}\right]_{e}}$ & $8.75 \times 10^{7}$ & $\mathrm{nM}$ \\
$K_{\max ,\left[\mathrm{Ca}^{2+}\right]_{e}}$ & $1.30 \times 10^{6}$ & $\mathrm{nM}$ \\
$C_{\operatorname{mem}}$ & $1.2 \times 10^{-11}$ & $\mathrm{~F}$ \\
\hline
\end{tabular}

Table S8: Parameters for SERCA mechanisms associated with S.2.4

\begin{tabular}{lll}
\hline Parameters & Values & Units \\
\hline$Q_{10}$ & 2.6 & \\
$V_{\max }$ & $9.09 \times 10^{6}$ & $\mathrm{nM} / \mathrm{s}$ \\
$K_{f}$ & $2.80 \times 10^{2}$ & $\mathrm{nM}$ \\
$K_{r}$ & $2.10 \times 10^{6}$ & $\mathrm{nM}$ \\
$H$ & 1.787 & \\
\hline
\end{tabular}

Table S9: Parameters for CaM/CN and NFAT cycle calculations shown in S.2.7

\begin{tabular}{lll}
\hline Parameters & Values & Units \\
\hline$k_{a b}$ & $1.0 \times 10^{-5}$ & $1 /\left(n M^{2} \times s\right)$ \\
$k_{b a}$ & 10.0 & $1 / \mathrm{s}$ \\
$k_{b c}$ & $1.0 \times 10^{-4}$ & $1 /\left(n M^{2} \times s\right)$ \\
$k_{c b}$ & $1.0 \times 10^{3}$ & $1 / \mathrm{s}$ \\
$k_{\text {on }, A}$ & $1.0 \times 10^{-2}$ & $1 /(n M \times s)$ \\
$k_{\text {off }, A}$ & 1.0 & $1 / \mathrm{s}$ \\
$k_{\text {on }, B}$ & $2.0 \times 10^{-6}$ & $1 /\left(n M^{2} \times s\right)$ \\
$k_{\text {off }, B}$ & 1.0 & $1 / \mathrm{s}$ \\
{$[C a M]_{\text {total }}$} & 100 & $\mathrm{nM}$ \\
{$[C N]_{\text {total }}$} & 67 & $\mathrm{nM}$ \\
\hline
\end{tabular}


Table S10: Parameters for phosphorylation of p38 and $\mathrm{Ca}^{2+}$ buffer calculations listed in S.2.6

\begin{tabular}{lll}
\hline Parameters & Values & Units \\
\hline$[p p 38]_{\text {total }}$ & 100 & \\
$k_{b, p p 38}$ & $8.51 \times 10^{-4}$ & $1 / \mathrm{s}$ \\
$k_{f, p p 38}$ & $1.1 \times 10^{-2}$ & $1 / \mathrm{s}$ \\
$k_{d, p p 38}$ & 150 & $\mathrm{nM}$ \\
$n_{p p 38}$ & 5 & \\
$B_{\max , F}$ & $2.5 \times 10^{4}$ & $\mathrm{nM}$ \\
$k_{\text {on }, F}$ & 0.15 & $1 /(\mathrm{nM} \times \mathrm{s})$ \\
$k_{\text {off }, F}$ & 23.0 & $1 / \mathrm{s}$ \\
$B_{\max , B}$ & $1.0 \times 10^{4}$ & $\mathrm{nM}$ \\
$k_{\text {on }, B}$ & 1.0 & $1 /(\mathrm{nM} \times \mathrm{s})$ \\
$k_{\text {off }, B}$ & $1.0 \times 10^{3}$ & $1 / \mathrm{s}$ \\
$B_{\max , S}$ & $1.4 \times 10^{5}$ & $\mathrm{nM}$ \\
$k_{\text {on }, S}$ & 0.1 & $1 /(\mathrm{nM} \times \mathrm{s})$ \\
$k_{\text {off }, S}$ & $6.5 \times 10^{4}$ & $1 / \mathrm{s}$ \\
\hline
\end{tabular}

Table S11: Parameters for simulating $\mathrm{TNF} \alpha$ synthesis and its exocytosis listed in S.2.8

\begin{tabular}{lll}
\hline Parameters & Values & Units \\
\hline$k_{\text {trnscrpt }}$ & $2.78 \times 10^{-4}$ & $1 / \mathrm{s}$ \\
$k_{\text {trnsl }}$ & $2.0 \times 10^{-4}$ & $1 / \mathrm{s}$ \\
$k_{\text {deg,TNFa }}$ & $1.38 \times 10^{-2}$ & $1 / \mathrm{s}$ \\
$k_{\text {deg,mRNA }}$ & $1.35 \times 10^{-4}$ & $1 / \mathrm{s}$ \\
$I C 50_{1}$ & 0.4 & \\
$n_{1}$ & 2 & \\
$I C 50_{2}$ & 75.0 & \\
$n_{2}$ & 5.5 & \\
$k_{\text {exp }, f}$ & $5.11 \times 10^{-4}$ & $1 /($ molecule $\times \mathrm{s})$ \\
$k_{\text {exp }, r}$ & $1.78 \times 10^{-4}$ & $1 / \mathrm{s}$ \\
$D_{n c}$ & 10.0 & $1 / \mathrm{s}$ \\
$D_{\text {exo }}$ & 5.0 & $1 / \mathrm{s}$ \\
$k_{d}$ & 25.0 & $\mathrm{nM}$ \\
\hline
\end{tabular}


Table S12: Parameters for simulating TNF $\alpha$ synthesis and its exocytosis listed in S.2.9

\begin{tabular}{lll}
\hline Parameters & Values & Units \\
\hline$k_{f, 1}$ & 0.008 & $1 / \mathrm{s}$ \\
$k_{b, 1}$ & 0.02 & $1 / \mathrm{s}$ \\
$k_{f, 2}$ & 0.1 & $1 / \mathrm{s}$ \\
$k_{b, 2}$ & 0.01 & $1 / \mathrm{s}$ \\
$k_{f, 3}$ & 0.01 & $1 / \mathrm{s}$ \\
$k_{b, 3}$ & 0.01 & $1 / \mathrm{s}$ \\
$k_{f, 4}$ & 0.00001 & $1 / \mathrm{s}$ \\
$k_{b, 4}$ & 0.01 & $1 / \mathrm{s}$ \\
$k_{f, 5}$ & 0.001 & $1 / \mathrm{s}$ \\
$k_{b, 5}$ & 0.1 & $1 / \mathrm{s}$ \\
$k_{f, 6}$ & 0.001 & $1 / \mathrm{s}$ \\
$k_{b, 6}$ & 0.01 & $1 / \mathrm{s}$ \\
$k_{\text {deg,1 }}$ & 0.05 & $1 / \mathrm{s}$ \\
{$[P 2 Y 12]_{\text {total }}$} & 100 & \\
{$[P I 3 K]_{\text {total }}$} & 100 & \\
{$[\text { Akt }]_{\text {total }}$} & 100 & \\
\hline
\end{tabular}

Table S13: Parameters for the degradation of ATP by NTPDase listed in S.2.12

Parameters Values Units

\begin{tabular}{lll}
\hline$k_{1, \text { deg }}$ & 0.002 & $1 / \mathrm{s}$
\end{tabular}

$\underline{k_{2, \operatorname{deg}} \quad 0.008 \quad 1 / \mathrm{s}}$


bioRxiv preprint doi: https://doi.org/10.1101/2021.06.19.448892; this version posted June 22, 2021. The copyright holder for this preprint (which was not certified by peer review) is the author/funder. All rights reserved. No reuse allowed without permission.

\section{S.2 Methods}

\section{S.2.1 Model equations}




\section{S.2.2 GPCR-model: Model 5 - Cuthbertson and Chay}

These equations are implemented and integrated with the mathematical expression for the $P 2 X$-mediated $\mathrm{Ca}^{2+}$ dynamics

$$
\begin{aligned}
& {[A T P]_{P 2 Y}=0.5+\frac{\text { Scale }}{\left(1+\frac{K d_{A T P, P 2 Y}}{[A T P]}\right)}} \\
& \text { where Scale }=3.7 \\
& {\left[I P_{3}\right]=[D A G]} \\
& d *=[D A G] / K_{d, P 2 Y} \\
& g *=\left[G_{\alpha}-G T P\right] / K_{g, P 2 Y} \\
& s *=\left[I P_{3}\right] / K_{s, P 2 Y} \\
& R_{P K C}=\frac{([P H]+[D A G])\left[C a^{2+}\right]_{i}}{\left(K_{c, P 2 Y}+\left[C a^{2+}\right]_{i}\right)\left(K_{p, P 2 Y}+[P H]\right)} \\
& R_{P L C}=\frac{(d *)^{n_{P 2 Y}}(g *)^{m_{P 2 Y}}}{\left(1+(d *)^{n_{P 2 Y}}\right)\left(1+(g *)^{m_{P 2 Y}}\right)} \\
& \frac{d\left[G_{\alpha}-G T P\right]}{d t}=-h g_{P 2 Y}\left[G_{\alpha}-G T P\right]+\left(\left[G_{\alpha, \text { total }}\right]-\left[G_{\alpha} G T P\right]\right) \frac{k_{g, P 2 Y}[A T P]_{P 2 Y}[P 2 Y]}{[A T P]_{P 2 Y}+k_{a, P 2 Y}} \\
& \frac{d[P 2 Y]}{d t}=k_{r e c, P 2 Y}\left([P 2 Y]_{t o t a l}-[P 2 Y]\right)-h_{r e c, P 2 Y} R_{P K C}[P 2 Y] \\
& \frac{d[D A G]}{d t}=l d_{P 2 Y}+k_{d, P 2 Y} R_{P L C}-h d_{P 2 Y}[D A G] \\
& \frac{d\left[\mathrm{Ca}^{2+}\right]_{i, I P_{3}}}{d t}=\frac{k_{c, P 2 Y}[\mathrm{ATP}]_{P 2 Y}(s *)^{n_{C a^{2+}, P 2 Y}}}{1+(s *)^{n_{C a^{2+}, P 2 Y}}}-K_{d e g, P 2 Y}\left[\mathrm{Ca}^{2+}\right]_{i, I P_{3}}
\end{aligned}
$$


bioRxiv preprint doi: https://doi.org/10.1101/2021.06.19.448892; this version posted June 22, 2021. The copyright holder for this preprint (which was not certified by peer review) is the author/funder. All rights reserved. No reuse allowed without permission. 


\section{S.2.3 P2X4 kinetic models - the model was taken from others but} implemented

\section{$P 2 X 4$ Dynamics}

$$
\begin{aligned}
& \kappa_{1, p}=2 k_{4}[A T P] \\
& \kappa_{1, m}=2 k_{3} \\
& \kappa_{2, p}=k_{6}[A T P] \\
& \kappa_{2, m}=3 k_{5} \\
& \kappa_{3, p}=H_{6} \\
& \kappa_{3, m}=0 \\
& K_{2}=\frac{\kappa_{2, p}}{\kappa_{2, m}} \\
& \alpha_{1, p}=\kappa_{1, p} \\
& \alpha_{1, m}=\frac{\kappa_{1, m}}{\left(1+K_{2}\right)} \\
& \alpha_{3, p}=\frac{\kappa_{3, p}}{\left(1+\frac{1}{K_{2}}\right)} \\
& \alpha_{3, m}=\kappa_{3, m} \\
& l_{1, p}=2 k_{4}[A T P] \\
& l_{1, m}=2 k_{3} \\
& l_{2, p}=k_{6}[A T P] \\
& l_{2, m}=3 k_{5} \\
& l_{3, p}=\alpha_{3, m} \\
& l_{3, m}=\alpha_{3, p} \\
& L_{2}=\frac{l_{2, p}}{l_{2, m}} \\
& \beta_{1, p}=l_{1, p} \\
& \beta_{1, m}=\frac{l_{1, m}}{1+L_{2}} \\
& \beta_{3, p}=\frac{l_{3, p}}{1+\frac{1}{L_{2}}} \\
& \beta_{3, m}=l_{3, m} \\
& D_{1}=1-D_{2}-D_{34}-C_{1}-C_{2}-Q_{12} \\
& \frac{d D_{2}}{d t}=3 k_{2}[A T P] D_{1}+H_{2}+\beta_{1, m} D_{34}-\left(k_{1}+\beta_{1, p}\right) D_{2} \\
& \frac{d C_{1}}{d t}=k_{1} C_{2}+H_{1} D_{1}-3 k_{2}[A T P] C_{1} \\
& \frac{d C_{2}}{d t}=3 k_{2}[A T P] C_{1}+\alpha_{1, m} Q_{1} 2-\left(k_{1}+H_{2}+\alpha_{1, p}\right) C_{2} \\
& \frac{d D_{34}}{d t}=\beta_{1, p} D_{2}+\beta_{3, m} Q_{12}-\left(\beta_{1, m}+\beta_{3, p}\right) D_{34} \\
& \frac{d Q_{12}}{d t}=\alpha_{1, p} C_{2}+\beta_{3, p} D_{34}-\left(\beta_{3, m}+\alpha_{1, m}\right) Q_{12}
\end{aligned}
$$




\section{$P 2 X 7$ Dynamics}

$$
\begin{aligned}
\text { Scale } & =\frac{1}{1+\left(\frac{k_{d}}{[A T P]}\right)^{n}} \\
k_{4} & =k_{4, \text { low }}-\operatorname{Scale}\left(k_{4, \text { low }}-k_{4, \text { high }}\right) \\
k_{6} & =k_{6, \text { low }}-\operatorname{Scale}\left(k_{6, \text { low }}-k_{6, \text { high }}\right) \\
h_{7} & =H_{7, \text { low }}+\operatorname{Scale}\left(H_{7, \text { high }}-H_{7, \text { low }}\right) \\
h_{1, p} & =2 k_{4}[\text { ATP }] \\
h_{1, m} & =2 k_{3} \\
h_{2, p} & =k_{6}[A T P] \\
h_{2, m} & =3 k_{5} \\
H_{2} & =\frac{h_{2, p}}{h_{2, m}} \\
y_{1, p} & =h_{1, p} \\
y_{1, m} & =\frac{h_{1, m}}{1+H_{2}} \\
D_{1} & =1-\left(D_{2}+D_{34}+C_{1}+C_{2}+Q_{12}\right) \\
\frac{d D_{2}}{d t} & =3 k_{2}[A T P] D_{1}+H_{2} C_{2}+y_{1, m} D_{34}-\left(k_{1}+y_{1, p}+H_{7}\right) D_{2} \\
\frac{d D_{34}}{d t} & =y_{1, p} D_{2}-y_{1, m} D_{34} \\
\frac{d C_{1}}{d t} & =H_{1} D_{1}+k_{1} C 2-3 k_{2}[A T P] C_{1} \\
\frac{d C_{2}}{d t} & =H_{7} D_{2}+3 k_{2}[A T P] C_{1}+y_{1, m} Q_{12}-\left(k_{1}+y_{1, p}+H_{2}\right) C_{2} \\
\frac{d Q_{12}}{d t} & =y_{1, p} C_{2}-y_{1, m} Q_{12}
\end{aligned}
$$

Estimation of P2X-induced inward current and $\mathrm{Ca}^{2+}$ influx

$$
\begin{aligned}
& I_{P 2 X}=\rho_{P 2 X} G_{12, P 2 X}\left(E_{12, P 2 X}-V_{P 2 X, \text { rev.pot. }}\right) Q_{12, P 2 X} \\
& J_{P 2 X}=\frac{-I_{P 2 X}}{2 F} \frac{f_{I_{C a^{2}+, P 2 X}} f_{\text {conv. }, P 2 X}}{\text { Vol } l_{\text {microglia }}}
\end{aligned}
$$




\section{S.2.4 NCX and SERCA model - Shannon-Bers model NCX}

$$
\begin{aligned}
& Q=Q_{10}^{\frac{T-310}{10}} \\
& K_{a}=\frac{1}{1+\left(\frac{K d_{A c t}}{\left[C a^{2}\right]_{i}}\right)^{n_{H}}} \\
& Z=\frac{F V}{R T} \\
& \delta=\left[\mathrm{Ca}^{2+}\right]_{e}\left[\mathrm{Na}^{+}\right]_{i}^{H_{\mathrm{Na}}} \\
& \sigma=\left[\mathrm{Na}^{+}\right]_{e}^{H_{N a}}\left[\mathrm{Ca}^{2+}\right]_{i} \\
& \text { top }=V_{\max }\left(-e^{(-1+\eta) Z} \sigma+\delta e^{\eta Z}\right) K_{a} Q \\
& \text { bot }=\left(1+k_{\text {sat }} Z e^{-1+\eta}\right) \\
& \times\left(K_{\max ,\left[\mathrm{Ca}^{2+}\right]_{i}}\left[N a^{+}\right]_{e}^{H_{N a}}\left(1+\left(\frac{\left[N a^{+}\right]_{i}}{K_{\max ,\left[N a^{+}\right]_{i}}}\right)^{H_{N a}}\right)\right. \\
& +K_{\max ,\left[\mathrm{Na} a^{+}\right]_{e}}^{H_{\mathrm{Na}}}\left(1+\frac{\left[\mathrm{Ca}^{2+}\right]_{i}}{K_{\max ,\left[\mathrm{Ca}^{2+}\right]_{i}}}\right)\left[\mathrm{Ca}^{2+}\right]_{i} \\
& \left.+K_{\max ,\left[\mathrm{Ca}^{2+}\right]_{e}}\left[\mathrm{Na}^{+}\right]_{i}^{\mathrm{H}_{\mathrm{Na}}}+\delta+\sigma\right) \\
& I_{N C X}=\frac{t o p}{b o t} \\
& J_{N C X}=\frac{C_{m e m} I_{N C X}}{\operatorname{Vol}_{M G} F}
\end{aligned}
$$

\section{SERCA}

$$
\begin{aligned}
Q & =Q_{10}^{\frac{T-310}{10}} \\
t o p & =\left(\frac{\left[C a^{2+}\right]_{i}}{K_{f}}\right)^{H}-\left(\frac{\left[C a^{2+}\right]_{E R}}{K_{r}}\right)^{H} \\
\text { bottom } & =1+\left(\frac{\left[C a^{2+}\right]_{i}}{K_{f}}\right)^{H}+\left(\frac{\left[C a^{2+}\right]_{E R}}{K_{r}}\right)^{H} \\
J_{E R t o C y, S E R C A} & =Q V_{\text {max }} \frac{\text { top }}{\text { bottom }} \\
J_{C y t o E R, S E R C A} & =r_{\text {vol,ER/Cyt }} J_{E R t o C y t}
\end{aligned}
$$

\section{S.2.5 Leak terms}

$$
\begin{aligned}
& J_{\text {ExtoCy,Leak }}=D_{\text {ExtoCy }}\left(\left[\mathrm{Ca}^{2}+\right]_{e}-\left[\mathrm{Ca}^{2+}\right]_{i}\right) \\
& J_{\text {ERtoCy,Leak }}=D_{E R t o C y}\left(\left[\mathrm{Ca}^{2}+\right]_{E R}-\left[\mathrm{Ca}^{2+}\right]_{i}\right)
\end{aligned}
$$




\section{S.2.6 Phosphorylation of p38 and buffers}

F,S, and B denote Fura-2, Calsequestrine in ER, and Extra unknown buffer in cytoplasm

$$
\begin{aligned}
{[p 38] } & =[p p 38]_{t o t a l}-[p p 38] \\
\frac{d[p p 38]}{d t} & =-k_{b, p p 38}[p p 38]+\frac{k_{f, p p 38}[p 38]}{\left(1+\left(\frac{k_{d, p p 38}}{\left[C a^{2+}\right]_{i}}\right)_{p p 38}^{n}\right)} \\
\frac{d\left[C a_{i}^{2+}: F\right]}{d t} & =k_{o n, F}\left(B_{\max , F}-\left[C a_{i}^{2+}: F\right]\right)\left[C a^{2+}\right]_{i}-k_{o f f, F}\left[C a_{i}^{2+}: F\right] \\
\frac{d\left[C a_{i}^{2+}: B\right]}{d t} & =k_{o n, B}\left(B_{\max , B}-\left[C a_{i}^{2+}: B\right]\right)\left[C a^{2+}\right]_{i}-k_{o f f, B}\left[C a_{i}^{2+}: B\right] \\
\frac{d\left[C a_{E R}^{2+}: S\right]}{d t} & =k_{o n, S}\left(B_{\max , S}-\left[C a_{E R}^{2+}: S\right]\right)\left[C a^{2+}\right]_{E R}-k_{o f f, S}\left[C a_{E R}^{2+}: S\right]
\end{aligned}
$$

\section{S.2.7 CaM/CN and NFAT cycle}

\section{Chemical Reaction Equations}

$$
\begin{aligned}
2 C a+C a M & \leftrightarrow C a_{2} C a M \\
2 C a+C a_{2} C a M & \leftrightarrow C a_{4} C a M \\
2 C a+C a_{2} C N & \leftrightarrow C a_{4} C N \\
C a_{4} C a M+C a_{4} C N & \leftrightarrow C a M C N \\
N F A T p_{c}+C a M C N & \leftrightarrow N F A T N_{c} \\
N F A T N_{c} & \rightarrow N F A T N_{n} \\
N F A T N_{n} & \leftrightarrow N F A T p_{n}+C a M C N \\
N F A T N p_{n} & \rightarrow N F A T p_{c}
\end{aligned}
$$

\section{CaM/CM Activation}

$$
\begin{aligned}
& {[\mathrm{CaM}]=[\mathrm{CaM}]_{\text {total }}-\left[\mathrm{Ca}_{2} \mathrm{CaM}\right]-[\mathrm{CaMCN}]-\left[\mathrm{Ca}_{4} \mathrm{CaM}\right]} \\
& {\left[\mathrm{Ca}_{2} \mathrm{CN}\right]=[\mathrm{CN}]_{\text {total }}-\left[\mathrm{Ca}_{4} \mathrm{CN}\right]-[\mathrm{CaMCN}]} \\
& \frac{d\left[\mathrm{Ca}_{2} \mathrm{CaM}\right]}{d t}=k_{a b}\left[\mathrm{Ca}^{2+}\right]_{i}^{2}[\mathrm{CaM}]-k_{b c}\left[\mathrm{Ca}^{2+}\right]_{i}^{2}\left[\mathrm{Ca}_{2} \mathrm{CaM}\right] \\
& +k_{c b}\left[\mathrm{Ca}_{4} \mathrm{CaM}\right]-k_{b a}\left[\mathrm{Ca}_{2} \mathrm{CaM}\right] \\
& \frac{d\left[C a_{4} C a M\right]}{d t}=-k_{c b}\left[C a_{4} C a M\right]-k_{o n, A}\left[C a_{4} C N\right]\left[C a_{4} C a M\right] \\
& +k_{b c}\left[\mathrm{Ca}^{2+}\right]_{i}^{2}\left[\mathrm{Ca}_{2} \mathrm{CaM}\right]+k_{o f f, A}[\mathrm{CaMCN}] \\
& \frac{d\left[C a_{4} C N\right]}{d t}=k_{o n, B}\left[\mathrm{Ca}^{2+}\right]_{i}^{2}\left[\mathrm{Ca}_{2} \mathrm{CN}\right]-k_{o n, A}\left[\mathrm{Ca}_{4} \mathrm{CN}\right]\left[\mathrm{Ca}_{4} \mathrm{CaM}\right] \\
& -k_{o f f, B}\left[C a_{4} C N\right]+k_{o f f, A}[C a M C N] \\
& \frac{d[C a M C N]}{d t}=-k_{o f f, A}[C a M C N]+k_{o n, A}\left[C a_{4} C N\right]\left[C a_{4} C a M\right]
\end{aligned}
$$




\section{NFAT Cycle}

$$
\begin{aligned}
\text { Ratio }_{a c t} & =0.1\left[\mathrm{Ca}_{4} C N\right]+1[\mathrm{CaMCN}] \\
{[C a M C N]_{N F A T} } & =[C N]_{\text {total }} \text { Ratio act } \\
N F A T_{N, c} & =-N F A T_{p, c}+N F A T t-N F A T_{N, n}-N F A T_{p, n} \\
R_{1} & =-k_{1, r}(1-a c t N) N F A T_{N, c}+k_{1, f} N F A T_{p, c}[C a M C N] \\
R_{2} & =k_{2, f} N F A T_{N, c} \\
R_{3} & =k_{3, f}(1-a c t N) N F A T_{N, n}-k_{3, r} N F A T_{p, n}[C a M C N] \\
R_{4} & =k_{4, f} N F A T_{p, n} \\
\frac{d N F A T_{p, c}}{d t} & =\frac{R_{4}}{C_{c n}}-R_{1} \\
\frac{d N F A T_{N, n}}{d t} & =-R_{3}+C_{c n} R_{2} \\
\frac{d N F A T_{p, n}}{d t} & =-R_{4}+R_{3}
\end{aligned}
$$

$C_{c n}$ is the volume fraction between cytosol and nucleus 


\section{S.2.8 TNF $\alpha$ synthesis}

$$
\begin{aligned}
& R_{\text {transcript }}=\left(\frac{k_{\text {trnscrpt }}[D N A]}{1+\left(\frac{I C 50_{1}}{N F A T_{N, n}}\right)^{n_{1}}}\right) \\
& R_{\text {translate }}=k_{\text {trnsl }}[\mathrm{mRNA}] \\
& R_{d e g, T N F \alpha}=k_{d e g, T N F \alpha}[T N F \alpha] \\
& R_{\text {deg, } m R N A}=\left(\frac{k_{\operatorname{deg}, m R N A}[m R N A]}{1+\left(\frac{[p p 38]}{I C 50_{2}}\right)^{n_{2}}}\right) \\
& R_{e x p, T N F \alpha}=k_{e x p, f}[D N A][T N F \alpha]-k_{e x p, r}[D N A: T N F \alpha] \\
& \frac{d[D N A]}{d t}=-R_{\exp , T N F} \\
& \frac{d[m R N A]}{d t}=R_{\text {transcript }, T N F}-R_{\text {deg, } R N A_{T N F}} \\
& \frac{d[D N A: T N F \alpha]}{d t}=R_{e x p, T N F \alpha} \\
& \frac{d[T N F \alpha]}{d t}=R_{\text {translate }}-R_{\text {deg,TNF }}-R_{\text {exp }, T N F \alpha} \\
& -D_{n c}\left([T N F a]-[T N F \alpha]_{c}\right) \\
& \frac{d[T N F \alpha]_{c}}{d t}=D_{n c}\left([T N F \alpha]-[T N F \alpha]_{c}\right) \\
& -\left([T N F \alpha]_{c}-[T N F \alpha]_{e}\right)\left(\frac{D_{e x o}}{1+\left(\frac{k_{d}}{\left(\left[C a^{2+}\right]_{i}-\left[C a^{2+}\right]_{o}\right.}\right)}\right) \\
& \frac{d[T N F \alpha]_{e}}{d t}=\left([T N F \alpha]_{c}-[T N F \alpha]_{e}\right)\left(\frac{D_{e x o}}{1+\left(\frac{k_{d}}{\left(\left[C a^{2+}\right]_{i}-\left[C a^{2+}\right]_{o}\right.}\right)}\right)
\end{aligned}
$$




\section{S.2.9 P2Y12-mediated Signaling and Chemotaxis}

$$
\begin{aligned}
\frac{d[P 2 Y 12]_{a c t}}{d t} & =k_{f, 1}\left([P 2 Y 12]_{t o t a l} \rho_{P 2 Y 12}-[P 2 Y 12]_{a c t}\right)[A D P]-k_{b, 1}[P 2 Y 12]_{a c t} \\
\frac{d\left[G_{i / o}\right]}{d t} & =[P 2 Y 12]_{a c t} k_{f, 2}-k_{d e g, 1}\left[G_{i / o}\right]^{2} \\
\frac{d\left[\text { Signal }_{C a^{2+}}\right]}{d t} & =k_{f, 6}\left(\left[\mathrm{Ca}^{2+}\right]_{i}-\left[\mathrm{Ca}^{2+}\right]_{o}\right)-k_{b, 6}\left[\text { Signal }_{\mathrm{Ca}^{2+}}\right] \\
\frac{[P I 3 K]_{s}}{d t} & =k_{f, 3} \text { Signal }_{C a^{2+}}\left([P I 3 K]_{t o t}-[P I 3 K]_{s}-[P I 3 K]_{a c t}\right)-k_{b, 3}[P I 3 K]_{s}-k_{f, 4}[P I 3 K]_{s}\left[G_{i / o}\right] \\
\frac{[P I 3 K]_{a c t}}{d t} & =k_{f, 4}[P I 3 K]_{s}\left[G_{i / o}\right]-k_{b, 4}[P I 3 K]_{a c t} \\
\frac{[p A k t]}{d t} & =k_{f, 5}\left([\text { Akt }]_{t o t a l}-[p A k t]\right)[P I 3 K]_{a c t}-k_{b, 5}[p A k t] \\
\text { Signal } l_{p A k t} & =\frac{1}{1+\left(\frac{\left.k d_{p A k t}\right)}{[p A k t]}\right)} \\
\text { Signal }_{\text {CaM }} & =\frac{1}{1+\left(\frac{k d_{C a M}}{\left[\text { Ca }_{4} \text { CaM }\right]-[\text { CaM }]_{0}}\right)} \\
\frac{V_{\text {mig }}}{d t} & =k_{f, \text { mig }}\left(\text { Signal }_{p A k t}+0.05 \text { Signal }_{\text {CaM }}\right)-k_{r, \text { mig }} V_{\text {mig }} \\
\frac{\text { Distance }}{d t} & =V_{\text {mig }}
\end{aligned}
$$

\section{S.2.10 $\left[\mathrm{Ca}^{2+}\right]_{E R}$ Homeostasis Equations}

$$
\frac{\left[C a^{2+}\right]_{E R}}{d t}=J_{E R t o C y t, S E R C A}-\frac{d\left[C a_{E R}^{2+}: S\right]}{d t}-J_{E R t o C y, \text { Leak }} \frac{V_{\text {microglia }}}{V_{E R}}-0.5\left[C a^{2+}\right]_{i, I P_{3}}
$$

\section{S.2.11 $\left[\mathrm{Ca}^{2+}\right]_{i}$ Homeostasis Equations}

$$
\begin{aligned}
\frac{d\left[\mathrm{Ca}^{2+}\right]_{i}}{d t} & =J_{P 2 X 7}+J_{P 2 X 4}+J_{E x t o C y, \text { Leak }}+J_{N C X}+J_{E R t o C y, \text { Leak }}+\left[\mathrm{Ca}^{2+}\right]_{i, I P_{3}} \\
& -\left(J_{C y t o E R, S E R C A}+\frac{d\left[C a_{i}^{2+}: F\right]}{d t}+\frac{d\left[C a_{E R}^{2+}: B\right]}{d t}\right. \\
& \left.+\frac{d\left[C a_{2} C a M\right]}{d t}+\frac{d\left[C a_{4} C a M\right]}{d t}+\frac{d\left[C a_{4} C N\right]}{d t}+\frac{d[C a M C N]}{d t}\right)
\end{aligned}
$$




\section{S.2.12 Degradation of ATP by NTPDase1}

$$
\begin{aligned}
& \frac{d[A T P]}{d t}=-k_{1, d e g}[A T P] \\
& \frac{d[A D P]}{d t}=k_{1, \operatorname{deg}}[A T P]-k_{2, \operatorname{deg}}[A D P] \\
& \frac{d[A M P]}{d t}=k_{2, \operatorname{deg}}[A D P]
\end{aligned}
$$

\section{S.3 How data was analyzed or Genetic Algorithm}

Fitting was done according to our genetic algorithm in (9). State variable values as a function of time were plotted in jupyter notebooks for analysis. The current version of the genetic algorithm we implemented in this work generates multiple child parameters based on the initial guess. The algorithm also takes multiple observable to prevent the parameter set from being limited to a single reference data. Lastly, this version allows us to accelerate the fitting by processing multiple parameters simultaneously. 


\section{S.4 Figures}

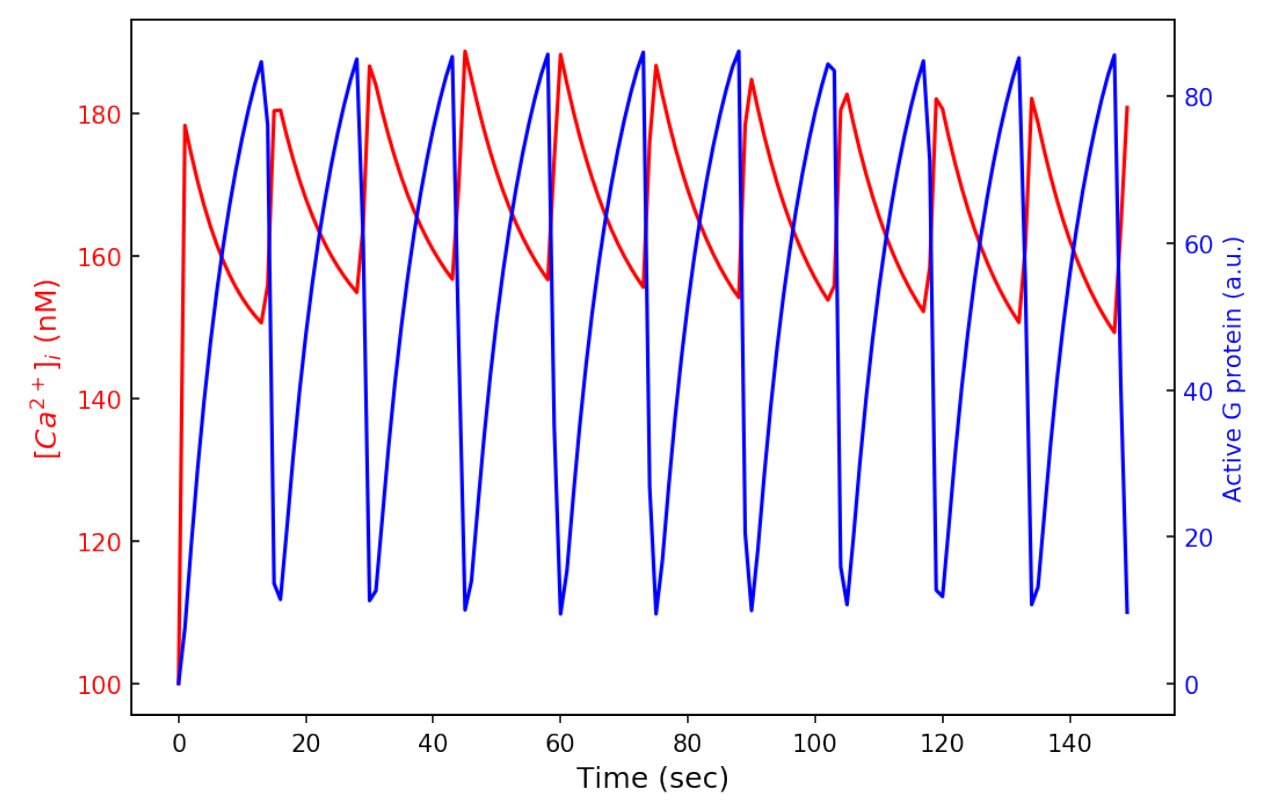

Figure S1: The demonstration of $\mathrm{Ca}^{2+}$ fluctuation mediated by P2Y-class receptor activation and its synchronization with the active $G_{\alpha q}$. . 

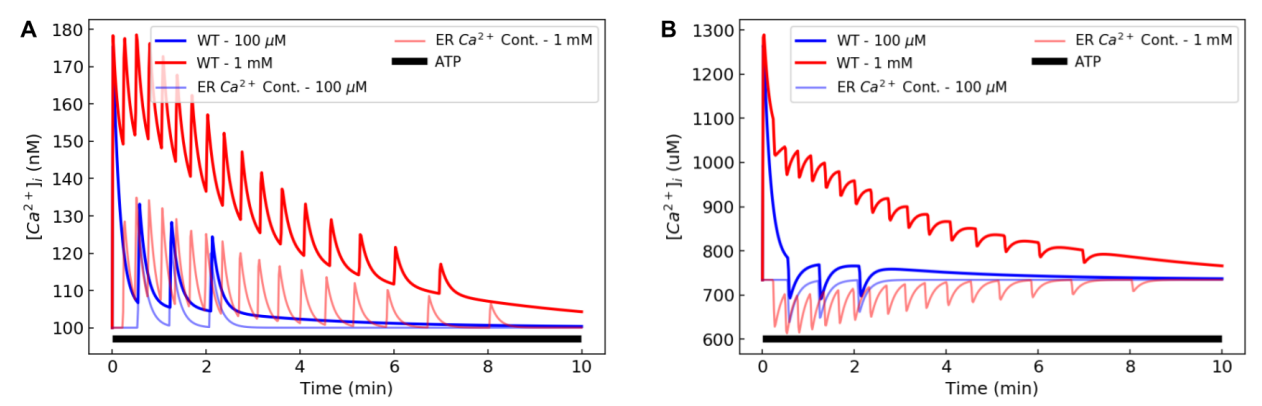

Figure S2: Comparison between $\mathrm{Ca}^{2+}$ transients induced by $\mathrm{ER} \mathrm{Ca}^{2+}$ release via $I P_{3}$-mediated pathway at $100 \mu \mathrm{M}$ and $1 \mathrm{mM}$ ATP concentrations in cytoplasm (A) and ER lumen (B). The WT microglia model was used for this prediction. The faded lines denote the contribution by $P 2 Y$ receptor activation that results in $\mathrm{ER} \mathrm{Ca}^{2+}$ release to the cytosolic domain. The data demonstrate the relationship between cytosolic and $\mathrm{ER} \mathrm{Ca}^{2+}$ transients, which suggest that roughly $43.7 \%$ of $\mathrm{Ca}^{2+}$ is drawn from the ER at low ATP vs. $33.3 \%$ at high ATP. . 
A

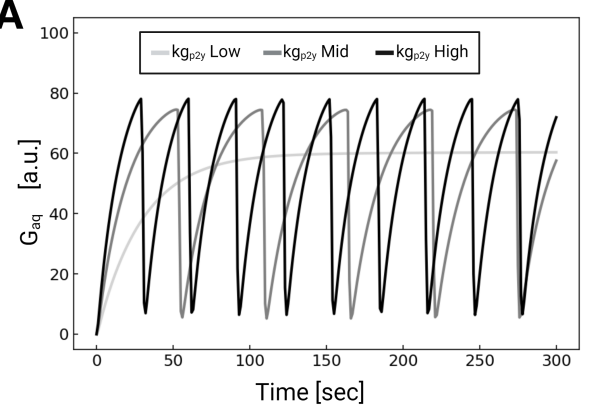

B

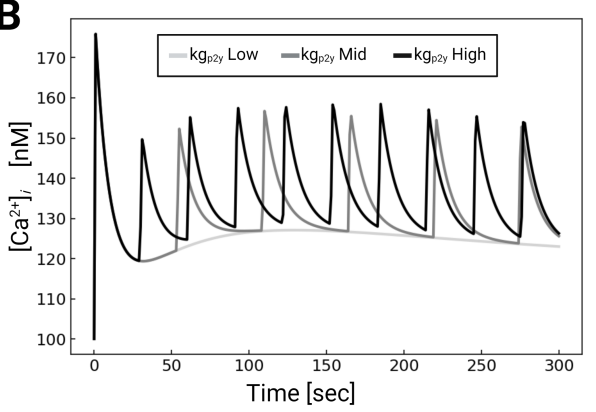

Figure S3: Oscillation of active $G_{\alpha q}$ and their corresponding intracellular $\mathrm{Ca}^{2+}$ transients with respect to $k g_{p 2 y}$ that controls the activation of $G_{\alpha q}$. . 


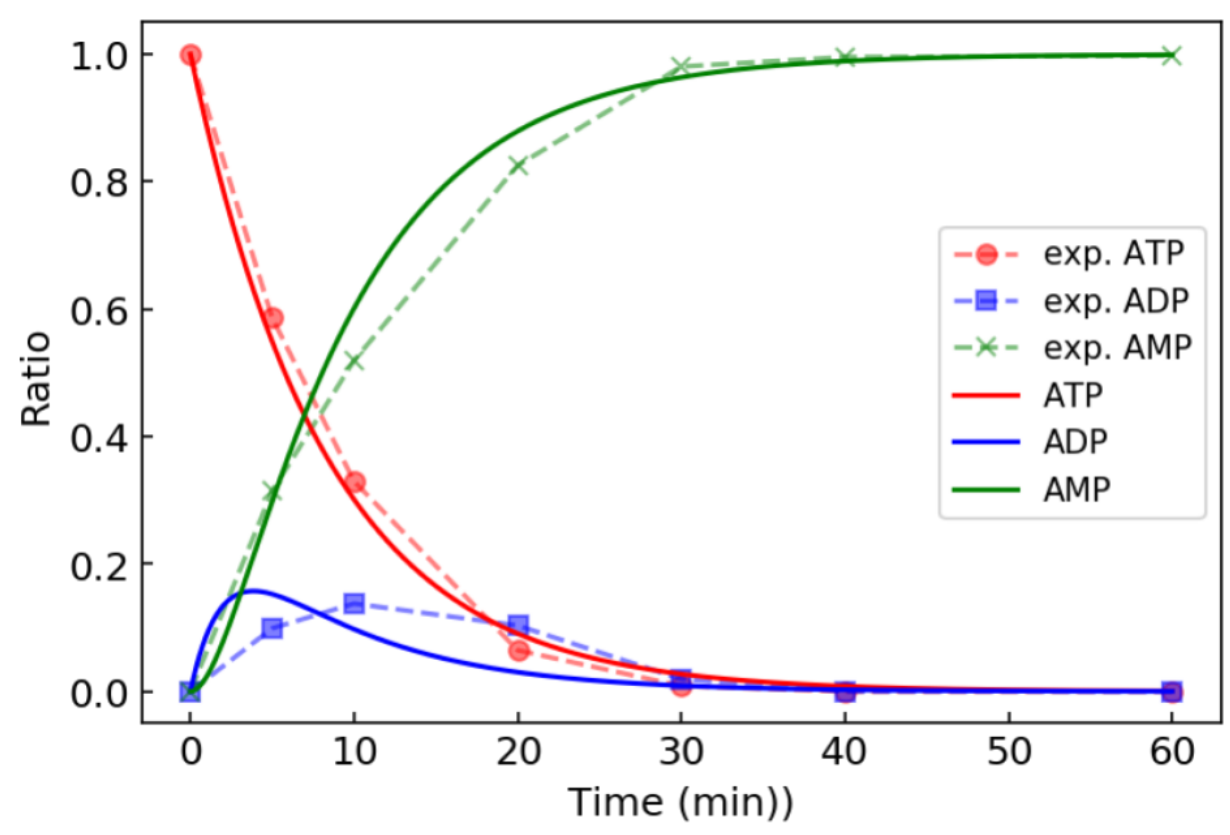

Figure S4: Validations of our model of ATP/ADP hydrolysis into AMP by CD39 against experimental data (dashed). Each nucleotide concentration was measured by Kukulski et al(47) in COS-7 cells . 


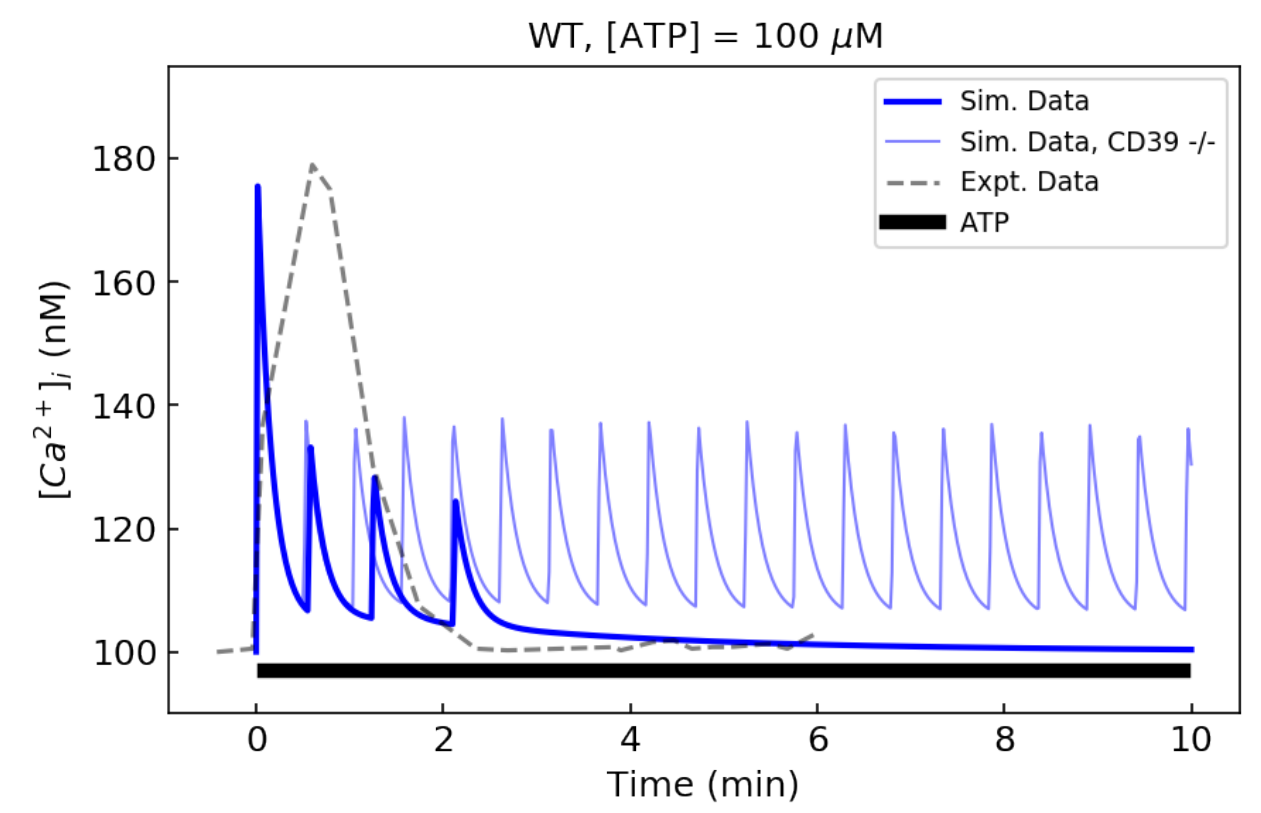

Figure S5: $\quad 100 \mu \mathrm{M}$ ATP treatment preferentially activates $P 2 X 4$ receptors and yields a similar $\mathrm{Ca}^{2+}$ transient to that of $P 2 X 7$. In both experiment and simulation, low ATP stimulation $(100 \mu \mathrm{M})$ applied to WT microglia was sufficient to activate all purinergic receptors except for $P 2 X 7$. . 


\section{A}

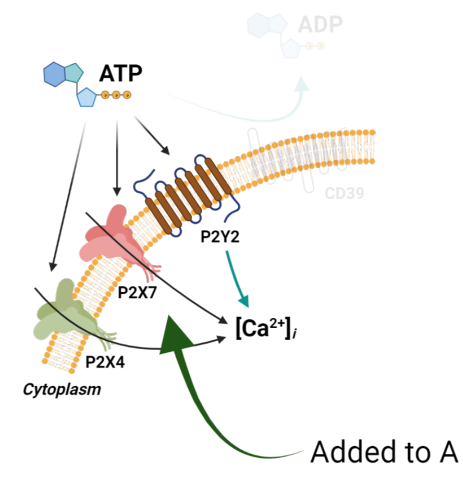

B

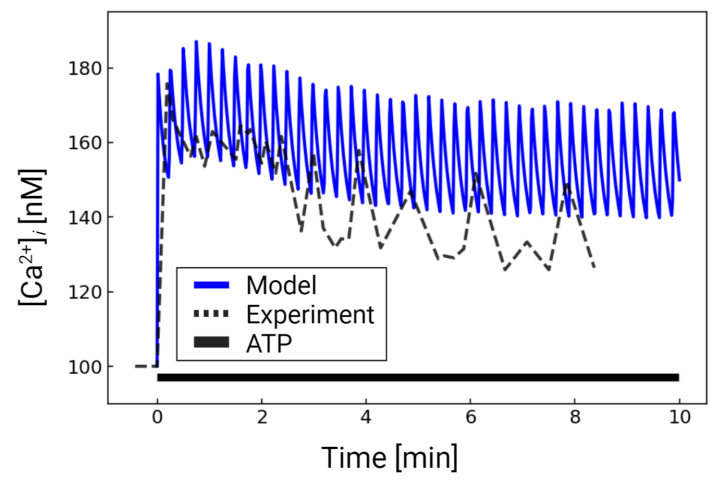

Figure S6: A) Schematic for $\mathrm{Ca}^{2+}$ waveforms generated in a control system comprising $\mathrm{P} 2 \mathrm{X} 4, \mathrm{P} 2 \mathrm{X} 7$ and $\mathrm{P} 2 \mathrm{Y} 2$ in response to $1 \mathrm{mM}$ ATP for 5 minutes, but exclusing CD39 nucleotidase activity. B) Comparison of predicted (blue) and experimentally-measured (35) (dashed) $\mathrm{Ca}^{2+}$ waveforms. . 

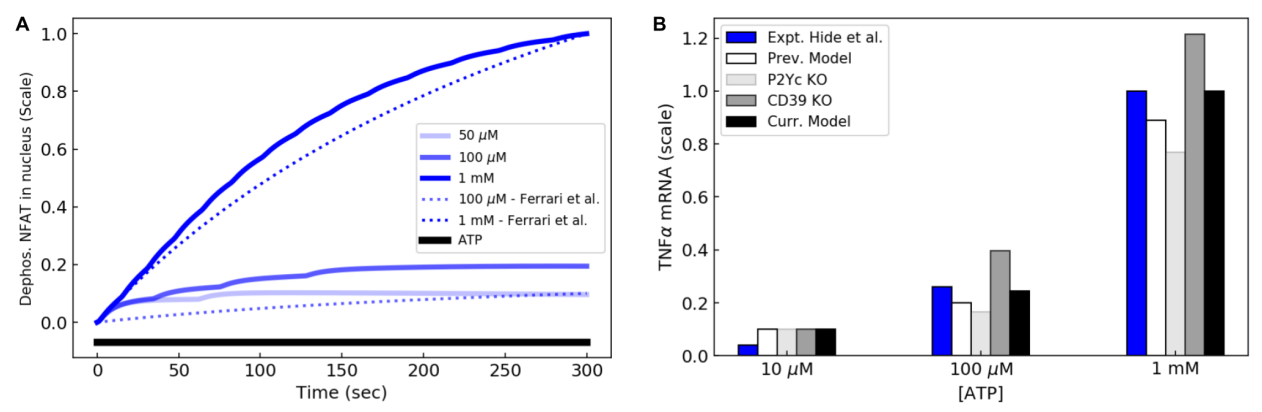

Figure S7: $\quad$ Predictions of dephosphorylated NFAT in nucleus over time (A) and $\mathrm{TNF} \alpha$ mRNA with various computation configurations and comparison to the previously developed model(9) with respect to amplitude of stimulation (5). All simulations in B) were performed for 5 minutes. The plot is in the unit of scale, whose basis is the maximum increment measured by the current model . 
A

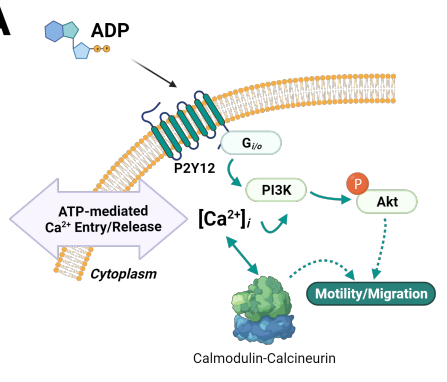

C

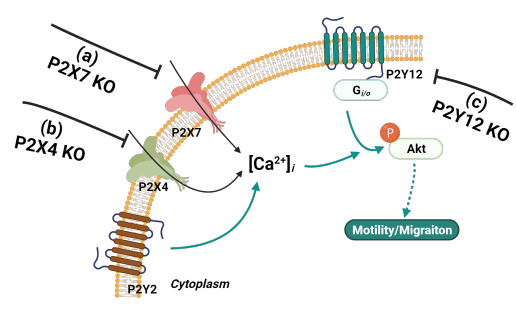

B

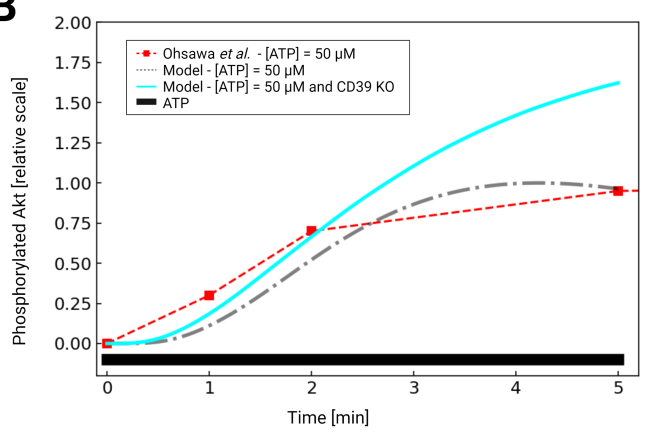

D

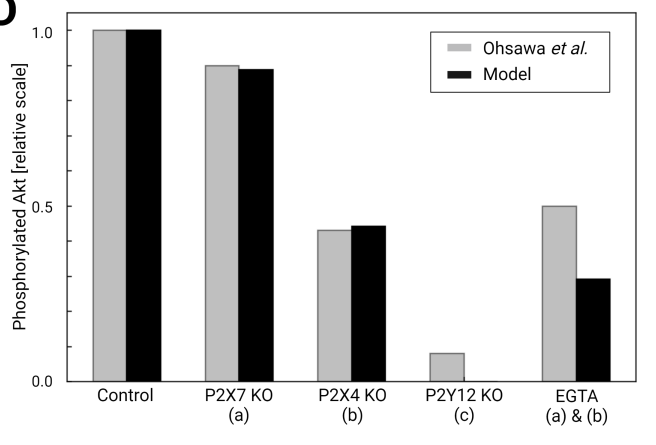

Figure S8: $\quad$ A) Schematic of Akt phosphorylation via P2Y12- and P2Ymediated $\mathrm{Ca}^{2+}$ signaling pathways in response to ATP. B) Predicted $p$ Akt expression as a function of time in response to $50 \mathrm{uM}$ ATP applied for 5 minutes with and without CD39 expression. Experimental data for 50 uM ATP from Ohsawa et al are presented in red. C) Schematic of P2Y12- and Ca-mediated migration in response to ATP, assuming control, P2X7 knockout (KO) (a), P2X4 KO (b) and P2Y12 KO (c) conditions. D) Predicted pAkt expression (black) versus experimental measurements by Ohsawa et al under control and a-c conditions. . 


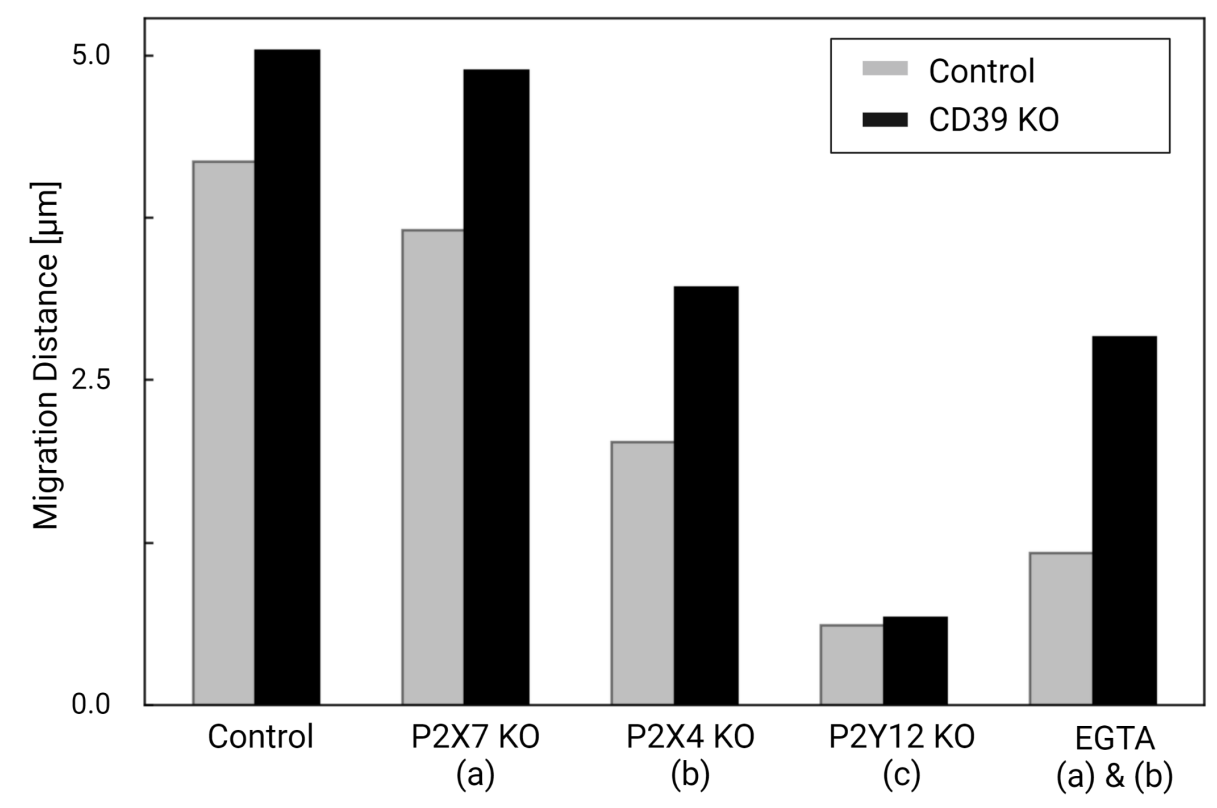

Figure S9: Migration comparison between WT and CD39 KO models . 

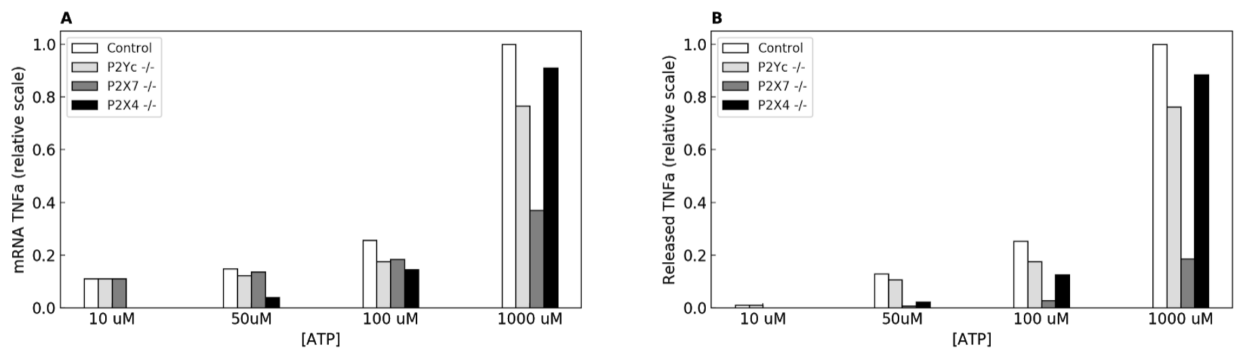

Figure S10: $\quad$ Prediction of TNF $\alpha$ mRNA expression(A), and $\mathrm{TNF} \alpha$ release(B) with conditions of $P 2 Y-/-, P 2 X 7-/-$, and $P 2 X 4-/-$. 
bioRxiv preprint doi: https://doi.org/10.1101/2021.06.19.448892; this version posted June 22, 2021. The copyright holder for this preprint (which was not certified by peer review) is the author/funder. All rights reserved. No reuse allowed without permission.

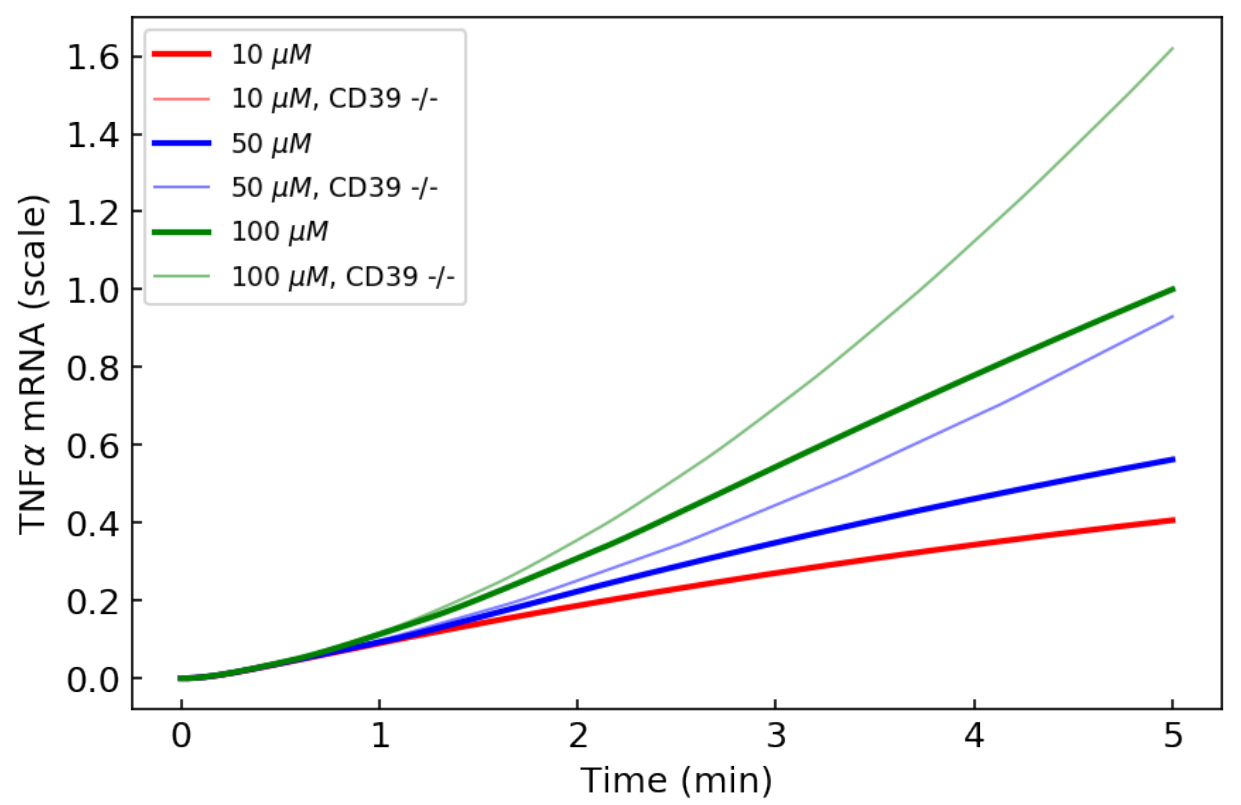

Figure S11: $\quad$ TNF $\alpha$ prediction with low ATP and with/without CD39 . 

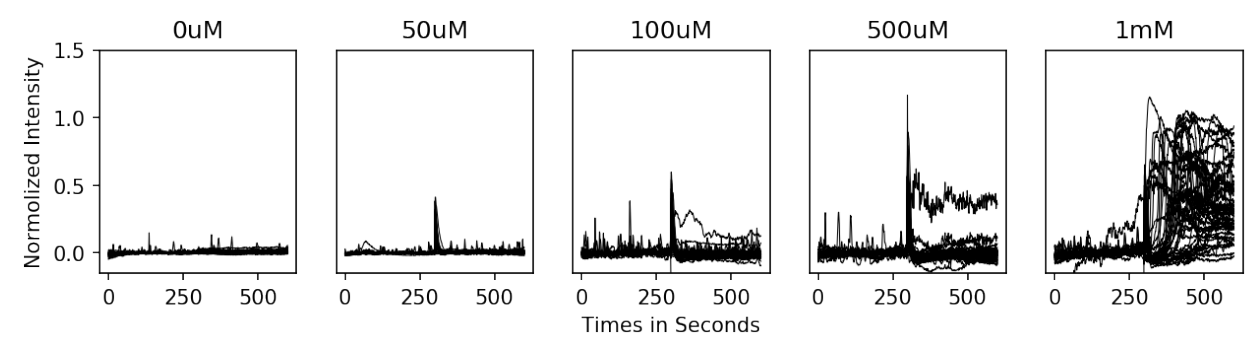

Figure S12: $\quad$ Traces of the fluorescence to measure the ATP-mediated $\mathrm{Ca}^{2+}$ transients in BV2 cells . 
bioRxiv preprint doi: https://doi.org/10.1101/2021.06.19.448892; this version posted June 22, 2021. The copyright holder for this preprint (which was not certified by peer review) is the author/funder. All rights reserved. No reuse allowed without permission.

A

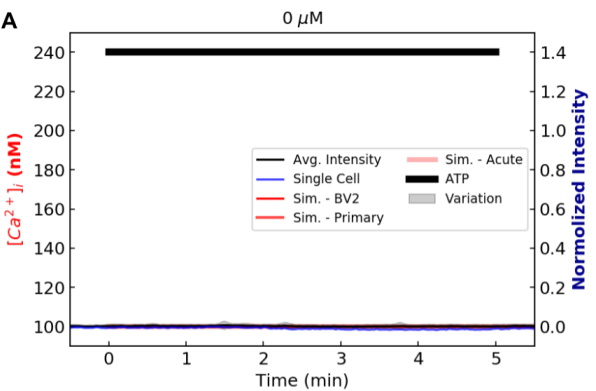

B

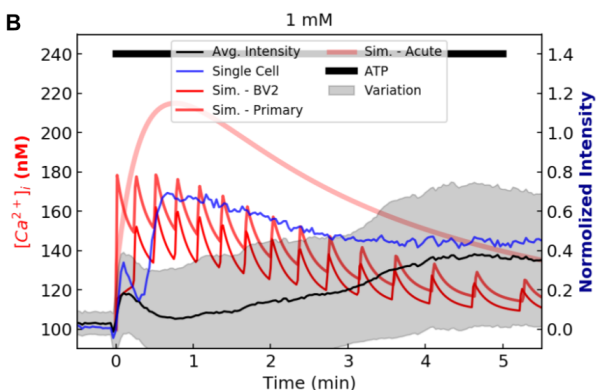

Figure S13: $\quad$ Predictions and experimental data of $\mathrm{Ca}^{2+}$ transients in BV2 with $0 \mu \mathrm{M}$ and $1 \mathrm{mM}$ ATP. . 


\section{S.5 Results}

\section{S.5.1 E-NTPDase (CD39): ATP decomposition to AMP}

Ectonucleoside triphosphate diphosphohydrolase-1 (E-NTPDase) also known as CD39 is reported to be present in the surface of microglial plasma-membrane and play an important role in microglial migration by balancing ATP and adenosine molecules (25). Using the generic ATP decomposition into ADP and AMP by CD39 introduced in the (47), we have added the ATP/ADP/AMP correlation to the previous model to properly differentiate the ATP-mediated and ADP-mediated activation of purinergic receptors. Therefore, the stimulant for P2X and P2Y-class that mediates $\mathrm{Ca}^{2+}$ fluctuations is ATP whereas P2Y12 is specifically stimulated by ADP.

\section{S.5.2 Migration}

In order to verify that migration occurs within the time intervals of which ATP -induced $\mathrm{Ca}^{2+}$ transients were measured, we report changes in above-threshold cell areas before and after ATP treatment.

\section{S.6 TNF $\alpha$ production mediated by purinergic receptors}

\section{S.6.1 Validation of TNF $\alpha$ mRNA data}

A primary consequence of ATP activation in microglia is the production of TNFa (33). Our previous model of ATP-triggered TNF $\alpha$ production in microglia we validated in (9) was limited to $P 2 X 4$ and $P 2 X 7$. We therefore confirm that the introduction of $P 2 Y$ and ectonucleotidase activity contributions maintains TNFa mRNA production rates consistent with experiment. We first evaluate the level of activated (dephosphorylated) NFAT, which is a prominent transcription factor driving TNFa mRNA synthesis In Fig. S7A we demonstrate an ATP dose-dependent increase in activated NFAT that remains in close agreement with experimental data from et al. In Fig. S7B, we illustrate the corresponding predicted TNFa levels. The data used for this validation was based on TNF $\alpha$ release measured by Iketa et al which was reported at under $1 \mathrm{mM}$ ATP treatment . For validation, we assumed that mRNA production was proportional to TNF release, and thus we rescaled the TNFa release data at 1 hour/1mM ATP to 5 minutes for $10 \mu \mathrm{M}-1 \mathrm{mM}$ ATP. The predicted TNF $\alpha$ mRNA levels for control remain in close agreement with comparable conditions imposed in Hide et al(33). The comparable results between the previous model (white) and current model (black) confirm that the P2Y/ENT implementations remain compatible with our previous validation data. This also suggests that the contributions of $P 2 Y$ do not significantly contribute to TNFa mRNA responses, as $P 2 Y$ knockdown in our model generally reduces the predicted mRNA levels by less than $10 \%$. We also present data for which ectonucleotidase activity is neglected, which demonstrate amplified TNFa mRNA production. The data indicate that $\mathrm{P} 2 \mathrm{Y}$ receptors do not significantly impact $\mathrm{TNF} \alpha$ production, owing to CD39 activity that attenuates their responses.

\section{S.7 Relative contribution of $P 2 X$ vs. $P 2 Y$ to cytokine pro- duction and migration}

The preceding section walked through the procedure and validity of modeling microglial responses to ATP stimulation. We note that a subtype of P2 receptors may mediate one or more pathways toward the production of pro-inflammatory 
cytokines, such as TNF $\alpha$, instead of the initiation of chemotaxis or vice versa. For instance, the $P 2 X$-mediated $\mathrm{Ca}^{2+}$-entry effectively promotes intracellular $\mathrm{Ca}^{2+}$-dependent signaling that leads to TNF $\alpha$ secretion. On the other hand, the activation of metabotropic receptors trigger various pathways whose outcomes include $\mathrm{Ca}^{2+}$ fluctuations and structural responses such as migration. To quantitatively analyze the functionality of specific $\mathrm{P} 2$ receptors in response to ATP, we carried out a series of simulations that selectively inhibit individual receptors. We additionally performed simulations with varying ATP concentrations to maximize the differential activation of $\mathrm{P} 2$ receptors.

Fig. 5 showcases the ATP-mediated mRNA transcription and secretion of TNF $\alpha$ and corresponding metrics of chemotaxis for each calculation configuration. We observed the expected absence of increase in basal $\mathrm{Ca}^{2+}$ levels in the $P 2 X 7 \mathrm{KO}$ simulation (Fig. 4). This resulted in a noticeable reduction in the TNF $\alpha$ mRNA transcription and release of matured cytokines compared to controls. On the contrary, in the lower range of ATP (up to $100 \mu \mathrm{M}$ ), the activation of $P 2 X 4$ receptors promote $\mathrm{Ca}^{2+}$ fluctuations sufficient for mRNA transcription. It is apparent that the differential degrees of ionotropic receptor activation throughout the tested ATP spectrum directly influence the $\mathrm{Ca}^{2+}$ entry, and it is well reflected on the obtained mRNA data. However, the inhibition of metabotropic receptors shows a relatively trivial change in the outcomes. The difference between inhibition of $P 2 Y 12$ and $P 2 Y$-class receptors is, though, that $P 2 Y$-class activation triggers $\mathrm{ER} \mathrm{Ca}^{2+}$ release, whereas $P 2 Y 12$-mediated secondary messenger elicits neither $\mathrm{Ca}^{2+}$ fluctuation nor TNF $\alpha$-associated pathways.

The predicted secretion of TNF $\alpha$ is consistent with the preceding mRNA data except for the data of $P 2 X 7 \mathrm{KO}$ setup. Suzuki et al(75) claimed that $\mathrm{TNF} \alpha$ release is correlated with the activation of $P 2 X 7$, the inhibition of which by brilliant blue $\mathrm{G}$ (BBG) resulted in up to $50 \%$ reduction in released $\mathrm{TNF} \alpha$ from microglia after 15-minute prolonged stimulation with $1 \mathrm{mM}$ ATP. The simulated TNF $\alpha$ release at the same ATP condition slightly overshoots the degree of reduction (nearly $60 \%$ ) in the production/release of TNF $\alpha$.

Simulations of chemotaxis display the relatively extensive dependency on $P 2 Y 12$ receptor activation (Fig. 5D). Silencing $P 2 Y 12$ receptors results in a substantial truncation of migration throughout the simulated range of ATP (more than $90 \%$ of reduction up to $1 \mu \mathrm{M}$, and $50 \%$ with $1 \mu \mathrm{MATP}$ ). Like with TNF $\alpha$ synthesis, the magnitude of reduction in migration induced by $P 2 X$ receptors varies as ATP concentration varies due to their varying sensitivities to ATP. Additionally, their deletion does not cause as severe a reduction in migration as knocking out $P 2 Y 12$ receptors. Overall, our prediction indicates the substantial involvement of $P 2 X 7$ receptors in the cytokine production; the $P 2 Y 12$ activation is crucial for invoking pathways associated with microglial chemotaxis. 


\section{Bibliography}

[1] Adams, D. J., Friedrich, O., Murphy, R. M., Kuenzel, K., Gilbert, D. F., Zacharewicz, E., Stebbing, M. J., Stokes, L., And Buttgereit, A. Store-Operated Ca2+ Entry (SOCE) and Purinergic Receptor-Mediated Ca2+ Homeostasis in Murine bv2 Microglia Cells: Early Cellular Responses to ATP-Mediated Microglia Activation. Frontiers in Molecular Neuroscience 9, October (2016), 1-15.

[2] Asatryan, L., Ostrovskaya, O., Lieu, D., and Davies, D. L. Ethanol differentially modulates p2x4 and p2x7 receptor activity and function in bv2 microglial cells. Neuropharmacology 128 (2018), 11-21.

[3] Barberì-Cremades, M., Gómez, A. I., Baroja-Mazo, A., Martínez-Alarcón, L., Martínez, C. M., De Torre-Minguela, C., AND PELEGRÍN, P. P2x7 receptor induces tumor necrosis factor- $\alpha$ converting enzyme activation and release to boost tnf- $\alpha$ production. Frontiers in immunology 8 (2017), 862.

[4] Bazzazi, H., Sang, L., Dick, I. E., Joshi-Mukherjee, R., Yang, W., AND YUE, D. T. Novel fluorescence resonance energy transfer-based reporter reveals differential calcineurin activation in neonatal and adult cardiomyocytes. Journal of Physiology 593, 17 (2015), 3865-3884.

[5] Bianco, F., Fumagalli, M., Pravettoni, E., D’Ambrosi, N., Volonte, C., Matteoli, M., Abbracchio, M. P., and Verderio, C. Pathophysiological roles of extracellular nucleotides in glial cells: differential expression of purinergic receptors in resting and activated microglia. Brain Research Reviews 48, 2 (2005), 144 - 156. Glial-Neuron Crosstalk in Neuroinflammation, Neurodegeneration and Neuroprotection.

[6] Cao, P., Donovan, G., Falcke, M., And Sneyd, J. A Stochastic Model of Calcium Puffs Based on Single-Channel Data. Biophysical Journal 105, 5 (2013), 1133-1142.

[7] Cao, P., Tan, X., Donovan, G., Sanderson, M. J., And Sneyd, J. A Deterministic Model Predicts the Properties of Stochastic Calcium Oscillations in Airway Smooth Muscle Cells. PLoS Computational Biology $\underline{10}, 8$ (2014), e1003783.

[8] Chessell, I. P., Michel, A. D., and Humphrey, P. P. A. Properties of the pore-forming P2X7 purinoceptor in mouse NTW8 microglial cells. British Journal of Pharmacology 121, 7 (1997), 1429-1437.

[9] Chun, B. J., Stewart, B. D., Vaughan, D. D., Bachstetter, A. D., And Kekenes-Huskey, P. M. Simulation of p2x-mediated calcium signalling in microglia. The Journal of Physiology 597, 3 (2019), 799-818.

[10] Cianciulli, A., Porro, C., Calvello, R., Trotta, T., Lofrumento, D. D., And Panaro, M. A. Microglia mediated neuroinflammation: Focus on pi3k modulation. Biomolecules 10, 1 (2020), 137.

[11] Clapham, D. E. Calcium signaling. Cell 131, 6 (2007), 1047-1058. 
[12] Collaborators, G. . U. N. D. Burden of neurological disorders across the us from 1990-2017: A global burden of disease study. JAMA Neurology 78, 2 (02 2021), 165-176.

[13] Cooling, M. T., Hunter, P., and Crampin, E. J. Sensitivity of NFAT cycling to cytosolic calcium concentration: Implications for hypertrophic signals in cardiac myocytes. Biophysical Journal 96, 6 (2009), 2095-2104.

[14] Crain, J. M., Nikodemova, M., and Watters, J. J. Expression of p2 nucleotide receptors varies with age and sex in murine brain microglia. Journal of neuroinflammation 6, 1 (2009), 24.

[15] Crain, J. M., And Watters, J. J. Microglial p2 purinergic receptor and immunomodulatory gene transcripts vary by region, sex, and age in the healthy mouse cns. Transcriptomics: open access 3,2 (2015).

[16] Cuthbertson, K., And Chay, T. Modelling receptor-controlled intracellular calcium oscillators. Cell calcium 12, 2-3 (1991), 97-109.

[17] De Pascalis, C., And Etienne-Manneville, S. Single and collective cell migration: the mechanics of adhesions. Molecular biology of the cell 28, 14 (2017), 1833-1846.

[18] Divolis, G., Mavroeidi, P., Mavrofrydi, O., and Papazafiri, P. Differential effects of calcium on pi3k-akt and hif- $1 \alpha$ survival pathways. Cell biology and toxicology 32, 5 (2016), 437-449.

[19] Dou, Y., Wu, H.-J., LI, H.-Q., QIn, S., WAng, Y.-E., Li, J., Lou, H.-F., Chen, Z., Li, X.-M., Luo, Q.-M., ET AL. Microglial migration mediated by atp-induced atp release from lysosomes. Cell research 22, 6 (2012), 1022-1033.

[20] Egan, T. M. Contribution of Calcium Ions to P2X Channel Responses. Journal of Neuroscience 24, 13 (mar 2004), 3413-3420.

[21] Erb, I., And Notredame, C. How should we measure proportionality on relative gene expression data? Theory in Biosciences 135, 1-2 (2016), $21-36$.

[22] Etienne, F., Mastrolia, V., Maroteaux, L., Girault, J.-A., GerVASI, N., AND Roumier, A. Two-photon imaging of microglial processes' attraction toward atp or serotonin in acute brain slices. JoVE (Journal of Visualized Experiments), 143 (2019), e58788.

[23] Fan, Y., Xie, L., And Chung, C. Y. Signaling pathways controlling microglia chemotaxis. Molecules and cells 40, 3 (2017), 163.

[24] Franco-Bocanegra, D. K., McAuley, C., Nicoll, J. A., And Boche, D. Molecular mechanisms of microglial motility: changes in ageing and alzheimer's disease. Cells 8, 6 (2019), 639.

[25] Färber, K., Markworth, S., Pannasch, U., Nolte, C., Prinz, V., Kronenberg, G., Gertz, K., Endres, M., Bechmann, I., Enjyoji, K., Robson, S. C., And Kettenmann, H. The ectonucleotidase cd39/entpdase1 modulates purinergic-mediated microglial migration. Glia 56, 3 (2008), 331-341. 
[26] Garcia-Guzman, M., Soto, F., Gomez-Hernandez, J. M., Lund, P. E., AND Stuehmer, W. Characterization of recombinant human $\mathrm{P} 2 \mathrm{X} 4$ receptor reveals pharmacological differences to the rat homologue. Molecular pharmacology 51, 1 (1997), 109-118.

[27] Gómez Morillas, A., Besson, V. C., and Lerouet, D. Microglia and neuroinflammation: What place for p2ry12? International Journal of Molecular Sciences 22, 4 (2021), 1636.

[28] Gyoneva, S., Orr, A. G., and Traynelis, S. F. Differential regulation of microglial motility by atp/adp and adenosine. Parkinsonism Related Disorders 15 (2009), S195 - S199. Proceedings of WFN XVIII World Congress on Parkinson's Disease and Related Disorders.

[29] Harris, J. J., Jolivet, R., And Attwell, D. Synaptic energy use and supply. Neuron 75, 5 (2012), 762-777.

[30] He, Y., Yao, X., Taylor, N., Bai, Y., Lovenberg, T., and BhatTACHARYA, A. Rna sequencing analysis reveals quiescent microglia isolation methods from postnatal mouse brains and limitations of bv2 cells. Journal of neuroinflammation 15, 1 (2018), 1-13.

[31] Heineke, J., And Molkentin, J. D. Regulation of cardiac hypertrophy by intracellular signalling pathways. Nature Reviews Molecular Cell Biology 7, 8 (2006), 589-600.

[32] Hickman, S. E., Kingery, N. D., Ohsumi, T. K., Borowsky, M. L., Wang, L.-C., Means, T. K., and El Khoury, J. The microglial sensome revealed by direct rna sequencing. Nature neuroscience 16, 12 (2013), 1896.

[33] Hide, I., Tanaka, M., Inoue, A., Nakajima, K., Kohsaka, S., InOUE, K., AND NAKATA, Y. Extracellular ATP triggers tumor necrosis factor alpha release from rat microglia. Journal of Neurochemistry 75, 3 (jan 2000), 965-972.

[34] Hoffmann, A., Kann, O., Ohlemeyer, C., Hanisch, U.-K., And Kettenmann, H. Elevation of basal intracellular calcium as a central element in the activation of brain macrophages (microglia): suppression of receptor-evoked calcium signaling and control of release function. The Journal of neuroscience : the official journal of the Society for Neuroscience $\underline{23}, 11$ (jun 2003), 4410-9.

[35] Ikeda, M., Tsuno, S., Sugiyama, T., Hashimoto, A., Yamoto, K., Takeuchi, K., Kishi, H., Mizuguchi, H., Kohsaka, S.-I., and YoshIOKA, T. Ca2 + spiking activity caused by the activation of store-operated ca2+ channels mediates tnf- $\alpha$ release from microglial cells under chronic purinergic stimulation. Biochimica et Biophysica Acta (BBA)-Molecular Cell Research 1833, 12 (2013), 2573-2585.

[36] Irino, Y., Nakamura, Y., Inoue, K., Kohsaka, S., and Ohsawa, K. Akt activation is involved in p2y12 receptor-mediated chemotaxis of microglia. Journal of Neuroscience Research 86, 7 (2008), 1511-1519. 
[37] Ito, D., Tanaka, K., Suzuki, S., Dembo, T., and Fukuuchi, Y. Enhanced expression of Iba1, ionized calcium-binding adapter molecule 1, after transient focal cerebral ischemia in rat brain. Stroke 32, 5 (2001), $1208-1215$.

[38] Jacobson, K. A., Costanzi, S., Joshi, B. V., Besada, P., Shin, D. H., Ko, H., Ivanov, A., and Mamedova, L. Agonists and antagonists for p2 receptors. In Novartis Foundation symposium (2006), vol. 276, Wiley Online Library, p. $\overline{58 .}$

[39] Jakovluevic, M., Lavrnja, I., Bozic, I., Milosevic, A., BuelobAba, I., Savic, D., SÉvigny, J., Pekovic, S., Nedelukovic, N., AND LAKETA, D. Induction of ntpdase1/cd39 by reactive microglia and macrophages is associated with the functional state during eae. Frontiers in neuroscience 13 (2019), 410.

[40] Jiang, P., Xing, F., Guo, B., Yang, J., Li, Z., Wei, W., Hu, F., Lee, I., Zhang, X., PAn, L., And Xu, J. Nucleotide transmitters atp and adp mediate intercellular calcium wave communication via p2y12/13 receptors among bv-2 microglia. PLOS ONE 12, 8 (08 2017), 1-16.

[41] Kekenes-Huskey, P. M., Eun, C., And McCammon, J. A. Enzyme localization, crowding, and buffers collectively modulate diffusion-influenced signal transduction: Insights from continuum diffusion modeling. The Journal of Chemical Physics 143, 9 (sep 2015), 094103.

[42] Kettenmann, H., Hanisch, U.-K., Noda, M., and Verkhratsky, A. Physiology of Microglia. Physiol Rev 91 (2011), 461-553.

[43] Khadra, A., Yan, Z., Coddou, C., Tomic, M., Sherman, A., And Stojilkovic, S. S. Gating properties of the P2X2a and P2X2b receptor channels: Experiments and mathematical modeling. The Journal of general physiology 139, 5 (2012), 333-348.

[44] Khadra, A., Yan, Z., Coddou, C., Tomić, M., Sherman, A., And Stojilkovic, S. S. Gating properties of the P2X2a and P2X2b receptor channels: Experiments and mathematical modeling. The Journal of general physiology 139, 5 (2012), 333-348.

[45] Kigerl, K. A., de Rivero Vaccari, J. P., Dietrich, W. D., Popovich, P. G., And Keane, R. W. Pattern recognition receptors and central nervous system repair. Experimental neurology 258 (2014), $5-16$.

[46] Kölsch, V., Charest, P. G., And Firtel, R. A. The regulation of cell motility and chemotaxis by phospholipid signaling. Journal of cell science 121, 5 (2008), 551-559.

[47] Kukulski, F., Lévesque, S., Lavoie, E., Lecka, J., Bigonnesse, F., Knowles, A., Robson, S., Kirley, T., And Sévigny, J. Comparative hydrolysis of $\mathrm{p} 2$ receptor agonists by ntpdases 1, 2, 3 and 8 . Purinergic signalling 1, 2 (2005), 193. 
[48] Li, S., Wang, Q., Wang, Y., Chen, X., And Wang, Z. Plc- $\gamma 1$ and rac1 coregulate egf-induced cytoskeleton remodeling and cell migration. Molecular endocrinology 23, 6 (2009), 901-913.

[49] Lively, S., And Schlichter, L. C. The microglial activation state regulates migration and roles of matrix-dissolving enzymes for invasion. Journal of neuroinflammation 10, 1 (2013), 1-14.

[50] Matyash, M., Zabiegalov, O., Wendt, S., Matyash, V., and KetTEnMAnN, H. The adenosine generating enzymes cd39/cd73 control microglial processes ramification in the mouse brain. PLoS One 12, 4 (2017), e0175012.

[51] Miller, A. M., ANd Stella, N. Microglial cell migration stimulated by atp and c5a involve distinct molecular mechanisms: Quantification of migration by a novel near-infrared method. Glia 57, 8 (2009), 875-883.

[52] Mogilner, A., And Edelstein-Keshet, L. Regulation of actin dynamics in rapidly moving cells: a quantitative analysis. Biophysical journal 83, 3 (2002), 1237-1258.

[53] Nagamoto-Combs, K., And Combs, C. K. Microglial Phenotype Is Regulated by Activity of the Transcription Factor, NFAT (Nuclear Factor of Activated T Cells). Journal of Neuroscience 30, 28 (jul 2010), 9641-9646.

[54] Nguyen, H. M., Blomster, L. V., Christophersen, P., And Wulff, H. Potassium channel expression and function in microglia: Plasticity and possible species variations. Channels 11, 4 (jul 2017), 305-315.

[55] Nguyen, H. M., di Lucente, J., Chen, Y.-J., Cui, Y., Ibrahim, R. H., Pennington, M. W., Jin, L.-W., Maezawa, I., And Wulff, H. Biophysical basis for kv1. 3 regulation of membrane potential changes induced by p2x4-mediated calcium entry in microglia. Glia 68, 11 (2020), $2377-2394$.

[56] Noda, Mami And Verkhratsky, A. Physiology of Microglia. In Neuroglia, B. Kettenmann, Helmut and Ransom, Ed., 3 ed. Oxford Univ Press, 2012, pp. 223-237.

[57] O’Brien, J. J., O’Callaghan, J. P., Miller, D. B., Chalgeri, S., Wennogle, L. P., Davis, R. E., Snyder, G. L., And Hendrick, J. P. Inhibition of calcium-calmodulin-dependent phosphodiesterase (pde1) suppresses inflammatory responses. Molecular and Cellular Neuroscience 102 (2020), 103449.

[58] OHsawa, K., Imai, Y., SAsAki, Y., AND KohsAKA, S. Microglia/macrophage-specific protein Iba1 binds to fimbrin and enhances its actin-bundling activity. Journal of Neurochemistry 88, 4 (jan 2004), 844-856.

[59] Ohsawa, K., Irino, Y., Nakamura, Y., Akazawa, C., Inoue, K., AND KoHsAKA, S. Involvement of p2x4 and p2y12 receptors in atp-induced microglial chemotaxis. Glia 55, 6 (2007), 604-616. 
[60] Petzold, L. Automatic Selection of Methods for Solving Stiff and Nonstiff Systems of Ordinary Differential Equations. SIAM Journal on Scientific and Statistical Computing 4, 1 (mar 1983), 136-148.

[61] Rahmaninejad, H., Pace, T., Bhatt, S., Sun, B., and KekenesHuskey, P. Co-localization and confinement of ecto-nucleotidases modulate extracellular adenosine nucleotide distributions. PLoS computational biology 16, 6 (2020), e1007903.

[62] Robson, S. C., SÉvigny, J., and Zimmermann, H. The e-ntpdase family of ectonucleotidases: structure function relationships and pathophysiological significance. Purinergic signalling 2, 2 (2006), 409.

[63] Sandefur, C. I., Boucher, R. C., and Elston, T. C. Mathematical model reveals role of nucleotide signaling in airway surface liquid homeostasis and its dysregulation in cystic fibrosis. Proc. Natl. Acad. Sci. 114, 35 (2017), E7272-E7281.

[64] Satulovsky, J., Lui, R., And Wang, Y.-L. Exploring the control circuit of cell migration by mathematical modeling. Biophysical journal 94, 9 (2008), 3671-3683.

[65] Shannon, T. R., Wang, F., Puglisi, J., Weber, C., And Bers, D. M. A mathematical treatment of integrated Ca dynamics within the ventricular myocyte. Biophysical Journal 87, 5 (2004), 3351-3371.

[66] Shimizu, S., Yoshida, T., Wakamori, M., Ishit, M., Okada, T., Takahashi, M., Seto, M., Sakurada, K., Kiuchi, Y., And Mori, $\mathrm{Y}$. Ca2+-calmodulin-dependent myosin light chain kinase is essential for activation of trpc5 channels expressed in hek293 cells. The Journal of physiology 570, 2 (2006), 219-235.

[67] Skupin, A., Kettenmann, H., and Falcke, M. Calcium signals driven by single channel noise. PLOS Computational Biology 6, 8 (08 2010), 1-13.

[68] Skupin, A., Kettenmann, H., Winkler, U., Wartenberg, M., Sauer, H., Tovey, S. C., Taylor, C. W., and Falcke, M. How does intracellular Ca2+ oscillate: by chance or by the clock? Biophysical journal 94, 6 (mar 2008), 2404-11.

[69] Smedler, E., AND UhlÉN, P. Frequency decoding of calcium oscillations. Biochimica et Biophysica Acta (BBA) - General Subjects 1840, 3 (2014), $964-969$.

[70] Sneyd, J., Keizer, J., And SAnderson, M. J. Mechanisms of calcium oscillations and waves: a quantitative analysis. FASEB Journal 9, 14 (1995), 1463-1472.

[71] Srinivas, M., And Patnaik, L. M. Genetic Algorithms: A Survey. Computer 27, 6 (1994), 17-26.

[72] Stebbing, M. J., Cottee, J. M., And Rana, I. The Role of Ion Channels in Microglial Activation and Proliferation-A Complex Interplay between Ligand-Gated Ion Channels, K+ Channels, and Intracellular Ca2+. Frontiers in Immunology 6 (oct 2015), 497. 
[73] Stephens, L., Milne, L., And Hawkins, P. Moving towards a better understanding of chemotaxis. Current Biology 18, 11 (2008), R485-R494.

[74] Stewart, B. D., Scott, C. E., McCoy, T. P., Yin, G., Despa, F., Despa, S., And Kekenes-Huskey, P. M. Computational modeling of amylin-induced calcium dysregulation in rat ventricular cardiomyocytes. Cell Calcium 71 (may 2018), 65-74.

[75] Suzuki, Y. Single-molecule rupture dynamics on multidimensional landscapes. Physical Review Letters (2010).

[76] Swiatkowski, P., Murugan, M., Eyo, U., Wang, Y., Rangaraju, S., OH, S., AND Wu, L.-J. Activation of microglial p2y12 receptor is required for outward potassium currents in response to neuronal injury. Neuroscience 318 (2016), $22-33$.

[77] Tatsumi, E., Yamanaka, H., Kobayashi, K., Yagi, H., Sakagami, M., AND NoGUCHI, K. Rhoa/rock pathway mediates p38 mapk activation and morphological changes downstream of $\mathrm{p} 2 \mathrm{y} 12 / 13$ receptors in spinal microglia in neuropathic pain. Glia 63, 2 (2015), 216-228.

[78] Toulme, E., And KhakH, B. S. Imaging P2X4 receptor lateral mobility in microglia: Regulation by calcium and p38 MAPK. Journal of Biological Chemistry 287, 18 (2012), 14734-14748.

[79] Towns, J., Cockerill, T., Dahan, M., Foster, I., Gaither, K., Grimshaw, A., Hazlewood, V., Lathrop, S., Lifka, D., Peterson, G. D., Roskies, R., Scott, J. R., And Wilkens-Diehr, N. XSEDE: Accelerating Scientific Discovery. Computing in Science \& Engineering 16, 5 (2014), 62-74.

[80] Trang, T., Beggs, S., Wan, X., And Salter, M. W. P2X4-ReceptorMediated Synthesis and Release of Brain-Derived Neurotrophic Factor in Microglia Is Dependent on Calcium and p38-Mitogen-Activated Protein Kinase Activation. Journal of Neuroscience 29, 11 (2009), 3518-3528.

[81] Tvrdik, P., AND Kalani, M. Y. S. In vivo imaging of microglial calcium signaling in brain inflammation and injury. International journal of molecular sciences 18, 11 (2017), 2366.

[82] Tyson, J. J. Biochemical oscillations. Computational Cell Biology 20 (2002), 230-260.

[83] Van Liedekerke, P., Neitsch, J., Johann, T., Alessandri, K., NasSOY, P., AND DRASDO, D. Quantitative agent-based modeling reveals mechanical stress response of growing tumor spheroids is predictable over various growth conditions and cell lines. PLoS computational biology 15, 3 (2019), e1006273.

[84] Xu, Z., Chen, Z.-M., Wu, X., Zhang, L., Cao, Y., and Zhou, P. Distinct molecular mechanisms underlying potassium efflux for nlrp3 inflammasome activation. Frontiers in Immunology 11 (2020), 3207. 
[85] Yan, Z., Khadra, A., Li, S., Tomic, M., Sherman, A., and StoJILKOviC, S. S. Experimental Characterization and Mathematical Modeling of P2X7 Receptor Channel Gating. Journal of Neuroscience 30, 42 (2010), 14213-14224.

[86] YaO, H., DuAn, M., YAng, L., And BuCh, S. Nonmuscle myosin lightchain kinase mediates microglial migration induced by hiv tat: Involvement of $\beta 1$ integrins. The FASEB Journal 27, 4 (2013), 1532-1548.

[87] Yaron, J., Gangaraju, S., Rao, M., Kong, X., Zhang, L., Su, F., Tian, Y., Glenn, H., And Meldrum, D. K+ regulates ca $2+$ to drive inflammasome signaling: dynamic visualization of ion flux in live cells. Cell death \& disease 6, 10 (2015), e1954-e1954.

[88] Zawadzka, M., Dabrowski, M., Gozdz, A., Szadujkis, B., Sliwa, M., Lipko, M., And Kaminska, B. Early steps of microglial activation are directly affected by neuroprotectant FK506 in both in vitro inflammation and in rat model of stroke. Journal of Molecular Medicine 90, 12 (dec 2012), 1459-1471.

[89] Zhang, S., Jin, G., Zhang, X.-S., And Chen, L. Discovering functions and revealing mechanisms at molecular level from biological networks. PROTEOMICS 7, 16 (2007), 2856-2869.

[90] Zhang, X., Ye, P., Wang, D., Liu, Y., CaO, L., Wang, Y., Xu, Y., AND ZHU, C. Involvement of rhoa/rock signaling in a $\beta$-induced chemotaxis, cytotoxicity and inflammatory response of microglial bv2 cells. Cellular and molecular neurobiology 39, 5 (2019), 637-650.

[91] Zhang, X., Zeng, L., Yu, T., Xu, Y., Pu, S., Du, D., And Jiang, W. Positive feedback loop of autocrine bdnf from microglia causes prolonged microglia activation. Cellular Physiology and Biochemistry 34, 3 (2014), 715-723.

[92] Zimmermann, H. 5'-nucleotidase: molecular structure and functional aspects. Biochemical Journal 285, Pt 2 (1992), 345. 